1 Change Starts With Me: An impact evaluation of a multiprofessional leadership 2 programme to support Primary Care Networks in the South East of England 3 4 
Abstract

Purpose This paper presents the impact evaluation findings from a multi-professional leadership programme commissioned in the South East of England to support Primary Care Networks (PCNs) to lead system improvement together. It identifies 1) programme impact at micro, and meso system ${ }^{1}$ levels; 2) a leadership impact continuum that can be used by individuals and teams to evidence impact of improvements in PCN practices; 3 ) the learning and development strategies that were effective; and 4) proposes implications for other networks.

\section{Research design/methods/approach}

Mixed methods underpinned by practice development methodology were used to explore the impact of the programme on two practitioner cohorts across 16 PCNs. Data was collected at the start, mid-point, and end of the eight-month programme.

\section{Findings}

Results illustrate an innovative approach to collective leadership development. A continuum of impact created with participants offers insight into the journey of transformation, recognising that 'change starts with me'. The impact framework identifies enablers, attributes and consequences for measuring and leading change at micro, meso-, and macro-levels of the health care system. Participants learned how to facilitate change and collaboratively problem solve through peer consulting which created a safe space for individuals to discuss workplace issues and receive multi-professional views through action learning. These activities enabled teams to present innovative projects to commissioners for service redesign, enabling their PCN to be more effective in meeting population health needs. The authors believe that this programme may provide a model for other PCNs in the United Kingdom and other place-based care systems internationally.

\section{Originality}

Offers insight into how to enable a journey of transformation for individuals and PCN teams to enhance team effectiveness and collective leadership for system wide transformation required by the NHS Long Term Plan (2019).

Key Words

Leadership impact, evaluation, clinical leadership, primary care networks, integrated care.

\footnotetext{
${ }^{1}$ We use the term system to describe all of the interdependent partners working together to provide integrated health and social care services to meet the needs of citizens, communities and local populations. Macro level = span the health and social care system, meso-level= organisation/service wide, micro-level= focus on teams or small functional units of staff working together from range of different professions.
} 


\section{Introduction}

Health services across the developed world are evolving rapidly, and over the coming years some of the most wide-ranging changes are expected to occur in primary care. The rise of primary care networks (PCNs) in the UK has shone a light on the ability of general practice teams to lead complex, rapidly changing policy and practice contexts especially in the light of the global COVID-19 pandemic.

Primary care in the UK includes the largest number of providers, and accounts for the largest proportion of patient contacts with the National Health Service (NHS), around 300 million per year in general practice alone (Watson 2019). PCNs, introduced across England in July 2019, are small networks of neighbouring general practices working together in multidisciplinary teams, typically serving around 20,000 to 50,000 people. They were designed to build on the pilots of new 'vanguard' models of integrated health care that had been developed as a result of the NHS Five Year Forward View (2014) to support local populations living with ever more complex long-term conditions and reduce the reliance on in-patient hospital care. They form the geographical basis for the development of integrated community health teams (NHS Long Term Plan, 2019), including mental health services, with a focus on providing proactive and anticipatory care. They aim to foster better collaboration among practices, pharmacists, district nurses, physiotherapists, social care, the voluntary sector, and others. Each PCN has a designated Clinical Director, usually but not always a general practitioner (GP), who is responsible for strategic and clinical leadership to help support change across primary and community health services, as well as overseeing service delivery. There were (as at May 2020), 1259 primary care networks in England (National Association of Primary Care). Each PCN holds a Directed Enhanced Service (DES) contract as a formal agreement across the constituent practices, with one practice holding this on behalf of those within the network. The DES contract provides funds for the network to operate seven new services specified by NHS England and Improvement, including social prescribing, practice-based pharmacy (structured medication reviews), enhanced health services for care homes, digital forms of access to general practice, community paramedic and physiotherapist support, more effective early cancer diagnosis, cardiovascular disease diagnosis and prevention, and local action to address health inequalities.

The introduction of Integrated Care Systems (NHS Long Term Plan, 2019), and greater collaboration through PCNs, all present leadership challenges for those working in primary care. Leaders will need to work collectively across networks and systems, to be visionary in designing future services, and more effective in leading their teams to help improve the quality of patient care and the health and well-being of local communities (Smith et al., 2020; Kings Fund 2020). While some of these collaborations existed before the new PCN contract was introduced, most are new and many of the clinicians who have been appointed as part-time clinical directors to lead these networks are new to a formal leadership role, and in particular to leading across organisations and within complex systems. The scale and complexity of the implementation and leadership challenge that faces them cannot be underestimated (Kings Fund 2020). The expectations of PCNs and clinical directors were challenging even before the pandemic, and the response to Covid-19 has demonstrated just how important their role can be in providing front line services (Kings Fund 2020).

This paper presents an impact evaluation of a multi-professional leadership programme which was commenced a year ahead of PCN policy being implemented nationally in the UK. It was 
commissioned in the South East of England to support Primary Care Networks to lead system improvement together, with a focus on building capacity for collective leadership in PCN teams. This was a novel approach because existing programmes largely focus solely on the leadership development of clinical directors of PCNs, with an emphasis on developing PCN structures and developing business and management skills. The paper presents an impact evaluation of the first two cohorts of participants' experiences between April 2018-November 2019. The evaluation identifies 1) programme impact at micro, meso, and macro system ${ }^{2}$ levels; 2) a leadership impact continuum that can be used by individuals and teams to evidence impact of improvements in PCN practices; 3 ) the learning and development strategies that were effective; and 4) proposes implications for other networks.

\section{Background}

The NHS Long Term Plan (2019) views PCNs as an essential building block of every Integrated Care System, yet with the rapid introduction and organisation around PCNs, the true value of networks can easily be misunderstood and get set up as a new bureaucracy merely shifting the burden around the system (Kings Fund 2020). Getting the design and implementation of the new PCNs 'right', will immeasurably improve the system for everyone (Kings Fund 2020, Smith et al., 2020). The rapidly changing pandemic landscape demands flexibility in working to meet ever evolving community health and wellbeing needs and services designed around public and primary health priorities. Increasing clinical demand and workforce shortages also mean that protecting time for learning and development is difficult for many in the health system but is crucial in supporting their response (Jackson et al., 2020; Kings Fund 2020).

While some PCNs have formed from groups of practices that have been working together for a long time, many are brand new relationships, or are dealing with the legacy of past conflicts that need to be resolved (Kings Fund, 2020; Smith et al., 2020; Swanwick and Varnam 2019). PCNs have also had to build new relationships with other parts of the health and care system and building relationships, improving dialogue and conflict management are consistent themes that appear in the literature (Kings Fund 2020; Smith et al., 2020; Swanwick and Varnam 2019).

A recent systematic review of clinical leadership and integrated primary care in Europe, identified that leaders' relational and organizational skills, as well as process-management and change-management skills, were considered important to improve care integration (Nieuwboer et al., 2019). Nieuwboer et al. (2019) concluded that good quality research on clinical leadership in integrated primary care is scarce. More profound knowledge is needed about leadership skills required for integrated-care implementation, as well as leadership support aimed at developing these skills (Nieuwboer et al., 2019). Other research studies identify that GP leadership skills in particular are impacted by a lack of formal leadership and management training, lack of capability, structural and role-related factors such as the private ownership structures and a fragmented care delivery system, the primacy of their clinical

\footnotetext{
${ }^{2}$ We use the term system to describe all of the interdependent partners working together to provide integrated health and social care services to meet the needs of citizens, communities and local populations. Macro level = span the health and social care system, meso-level= organisation/service wide, micro-level= focus on teams or small functional units of staff working together from range of different professions.
} 
121 identity in daily work, lack of influence, money, diversity of objectives, time, and reliance on 122 ad-hoc solutions for solving leadership challenges (Storey et al., 2019; Hana and Rudebeck, 123 2011; O'Riordan and McDermott, 2012). Furthermore, a lack of leadership training in 124 undergraduate medical training and a reported lack of confidence among GP trainers to teach 125 and assess clinical leadership (Simons and Woods, 2015), means that new and innovative 126 ways of facilitating leadership development for GPs and the wider multi-professional team in 127 PCNs is needed (Smith et al., 2020).

128 Swanwick and Varnam (2019) identify four key leadership challenges in primary care. The first 129 is that leaders will be expected to innovate in every aspect of how care is delivered, whilst 130 sustaining high quality services day to day in a well-led PCN. Secondly, primary care 131 leadership is expected to work increasingly across its internal boundaries, as networks of 132 practices and associated neighbourhood teams, share resources and collaborate to improve 133 care and provide innovative services for patients and their populations. Thirdly, as well as 134 leadership of primary care, leadership from primary care is pivotal to the future development 135 of health and care systems more widely. Playing a greater role in leading integrated care 136 systems requires strategic system leadership at various levels, often simultaneously, requiring 137 juggling peer, team, organisation, sector, community and system leadership to be effective 138 (Swanwick and Varnam, 2019). Finally, they report a number of historical workplace 139 challenges that impact on funding and support for leadership learning and development.

There is very little published evidence of initiatives aimed at improving PCN collaboration and leadership currently in the literature. This has driven development of a place-based learning culture across one integrated care system Training Hub, recognised as essential for supporting such large-scale change (Middleton et al; in press). Downey and Waters (2005) previously recognised the need to develop the primary care team as a learning organisation, identifying team action learning as essential for enabling better understanding of team roles, and improving communication in the wider primary healthcare team- pre-requisites for establishing a learning culture within an organisation (Cardiff et al., 2020). They reported that a facilitated multidisciplinary problem-based learning approach in teams helps to encourage open systems thinking and learning at individual and team level (Downey and Waters, 2005). This approach in turn helps to empower individuals to develop their own capabilities and challenge traditional mental models associated with hierarchical patterns of behaviours in teams (Downey and Waters, 2005).

If PCNs are to drive integrated system wide transformation in delivery of services, radical transformation towards informal leadership roles is required, where everyone can be a leader of something and a follower on other things. Leadership development needs to shift away from the traditional and outdated demand and control models which value top down heroic, formal command and control models predominant in organisational leadership theories(West et al., 2015; de Zulueta, 2016), which emphasize individual leadership qualities and providing vision for others (Kings Fund 2011). A new understanding is required of how leadership is exercised and what it means to be a leader. This will involve paying attention to collective identity and shared purpose, and different approaches towards power and change. Collective leadership that creates compassionate and inclusive cultures, inspires commitment to create healthy communities, mobilises large-scale change across a geographical area, and engages local people and service users is needed. Embracing collective capability and endeavour when 165 acting and learning together to shape the culture (NHS Improvement, 2019; Manley et al., 
2019; Sharp, 2018; West et al., 2014); recognising the value of shared values, a distributive and adaptable focus, not just across organisations but also across boundaries, networks and systems (de Zulueta, 2016), and the social capital embedded in people with different expertise working together through connected relationships and networks (Der Zjipp et al., 2016) should be central to PCN leadership development programmes.

There is a need, therefore, for PCNs to work together across the system shifting the focus from managing today's business to designing future services and leading change. Alongside the responsibility to run safe and effective services, primary care leaders need to lead significant programmes of service redesign and ensure a vision of improved ways of working is realised. Leadership development provides a mechanism to achieve high performing teams and thriving workplaces (Cardiff et al., 2020), through using learning and development processes effective in other health contexts (Akhtar et al., 2016).

The Medway \& Swale Multi-Professional Leadership Programme aimed to plug the gap that exists in supporting PCN teams to be effective in leading sustainable improvement plans, and the impact evaluation presented in the next section of the paper presents insights to inform strategies that might be helpful to other PCNs nationally and internationally.

\section{The programme, recruitment and selection process}

The 'Medway \& Swale Multi-Professional Leadership Programme' initiative was a unique collaboration between the Medway Clinical Commissioning Group, the North Kent Training Hub, part of Health Education England (co-funders), the Institute of Medical Sciences at Canterbury Christ Church University and the England Centre for Practice Development, a national centre for applied health research.

The programme aimed to address the key objectives of the General Practice Forward View (NHS England, 2016) and the NHS Long Term Plan (NHS England, 2019) through 8 days of leadership Master Classes spread over 8 months to develop:

- self-awareness of participants' individual and collective professional leadership impact;

- capacity and capability for leadership, innovation and improvement within their workplace teams and across PCNs.

$<$ Insert Box I Programme Aims $>$

The learning and development processes included active and action learning and collaborative co-creation of a shared vision for leadership and a leadership impact framework, through masterclasses and workshops over the eight months. Such approaches emphasise reflective learning and the identification of the impact of own actions on self and others. Monthly gaps between sessions were designed to enable participants to reflect on their own PCN practises, and test out new ideas experienced within the learning spaces with their practice teams using the workplace as the main resource for learning, developing and improving the quality of care and services within their practice. A key component of each day was the collaborative problem-solving method, called 'Peer Consulting'. Here, split into smaller groups, each group aimed to discuss a current workplace issue volunteered by an individual, 
206 tightly facilitated with set rules within a 45 minute time frame by another member of the group.

207 This created a safe space for discussion, building trust and relationships as well as building 208 facilitation skills as the facilitator role was rotated throughout the programme with feedback on 209 performance.

210 The key activities in the programme mirrored the skills required for sustainable systems 211 transformation (Manley \& Jackson, 2020) and for developing effective workplace cultures and 212 high performing teams-collective leadership; creating a safe environment and psychological 213 safety for critical thinking and creative learning (Cardiff et al., 2020) identified in Box II. 214 Participants were required to present a collaborative service improvement project to the 215 governing body of Medway Clinical Commissioning Group at the end of the programme to 216 improve services locally within their PCN. The range of projects suggested could include i) 217 how patients were formatively engaged in co-designing service improvements; ii) a joint 218 project between clinician and manager that delivers better quality of care or better patient 219 experience; iii) implementation of a system wide pathway; iv) a practice-based service 220 improvement involving engagement of a multi-disciplinary team; v) implementation of a digital 221 based solution to improve patient access.

222

223

224

225

226

227

228

229

230

231

232

233

234

235

236

237

238

239

240

241

242

243

244

245

246

<insert Box II Main Learning and Development Processes>

The programme was advertised through local primary care communications channels as a funded programme and participants recruited on a first come first served basis ensuring participant representation across the geographic region. Two cohorts of GPs (16), practice nurses (4) (PNs), practice managers (9) (PMs), and pharmacists (1) participated in the programme, learning together how to lead change and improvements in their locality networks. Practitioners from seven GP practices participated in cohort 1 (14 participants), and nine GP practices in cohort 2 (16 participants).

\section{Methods}

A mixed methods approach to impact evaluation underpinned by practice development methodology was used by the England Centre for Practice Development, commissioned for their expertise in practice-based research and collaborative approaches to person centered sustainable health systems transformation (Manley and Jackson, 2020). The impact evaluation aimed to address three key questions:

1. What impact has the programme had on individual participants in their leadership practice?

2. What impact has the programme had on participants' teams, practices and workplace?

3. What learning and development processes have been influential on the leadership strategies used by participants in the workplace to achieve impact?

Participants were simultaneously supported to explore their own leadership journey and identify its impact on their PCN teams and services. The assumptions underpinning the approach are identified in Box III.

<insert Box III Assumptions underpinning the approach to impact evaluation> 
247 The Economic and Social Research Council (ESRC) identify the value of co-productive 248 research as offering potential for impact academically and socially defined as 'research 249 undertaken with rather than on people in a collaborative, iterative process of shared learning' 250 (ESRC, 2020, https://esrc.ukri.org/research/impact-toolkit/what-is-impact/). The ESRC define 251 impact as ' demonstrable contribution that excellent research makes to society and the 252 economy' (https://esrc.ukri.org/research/impact-toolkit/what-is-impact/). 'Research' can be 253 substituted with either 'practitioner research' or 'programme theory' for similar societal 254 contributions that benefit individuals and organisations, including, capacity building through 255 technical and personal skill development, for practice or service provision and contributing to 256 understanding.

257 The learning and development processes summarised in Box II therefore become the main 258 methods for gathering data to answer the first two evaluation questions, supplemented with 259 process evaluation data collected at the end of each study day to provide additional insights 260 into the learning and development strategies influencing achievement of impact. Data was 261 collected at the beginning, mid-point and end of the programme. Table I provides detail about 262 the methods used, when they were used, who and how the data was analysed and the 263 outcomes from triangulating the datasets to answer the evaluation questions.

Data from each method, drawn from different sources (collaborative data; individual data; documentary data; stakeholder data) were analysed independently and triangulated to address the impact questions as well as develop a comprehensive understanding of the phenomena (Patton, 1999), in this case, the leadership journey of participants and its impact.

<insert Table I Impact Evaluation questions, data collection methods, analysis and triangulation outputs >

Findings

273

274

275

276

277

278

279

280

281

282

283

284

285

286

287

288

The findings are summarised under each impact evaluation question triangulating data from multiple sources (Table I). Data themes are presented at the start of participants' leadership journeys, across the journey's continuum and at the end to enable the impact to be summarised.

Question 1: What impact has the programme had on individual participants in their leadership practice?

These findings are drawn from the data analysis themes from using methods 1, 2, 3 and 5 in Table I. They reflect the participants leadership journey and impact on individual participants' leadership practice at the beginning, mid-point and end of the programme.

At the beginning of the programme, the strongest themes emerging from analysing individuals' Hopes, Fears and Expectations (Table I, method 2) for cohort 1 were participants :

- hoped to become more confident as a leader, to engage with all staff, develop leadership strategies and skills, learn how to influence culture and effect change.

- feared failure, being vulnerable, and stepping out of their comfort zone, and

- expected to embrace learning specific improvement tools, becoming more self aware and learn from others. 
289

290

291

292

293

294

295

296

297

298

299

300

301

302

303

304

305

306

307

308

309

310

311

312

313

314

315

316

317

318

319

320

321

322

323

324

325

326

327

328

329

330

331

332

333
In Cohort 1, self-assessment using cognitive mapping statements undertaken by 14 participants $(n=14)$, showed the majority were confident about making a difference to the staff they worked with and service users, half were confident about demonstrating impact on both staff and service users, but only $25 \%$ knew how to evaluate their impact. Box IV illustrates this analysis.

<Insert Box IV Levels of experience of measuring impact among participants >

For cohort 2, a modified approach was adopted and the 16 participants $(n=16)$ were asked to identify their top three leadership opportunities and challenges. The obstacles identified were themed by participants as 1) changing mind-sets, 2) breaking hierarchy and 3) meeting patient expectations. The challenges: 1) time constraints, 2) personality clashes within the team and how to manage these; and 3) keeping up to date with the pace of change. Cohort 2 participants identified being anxious about whether they could be an effective leader and whether they were "getting it wrong" (C2, P5, P7).

These themes provide a common picture of the starting point for most participants at the beginning of their leadership journey

At the end of the programme, analysis of cumulative data from the reflective reviews (See Table I, method 5) based on a reflective framework developed by Johns (2005), identified the following three themes of learning and impact on self as a leader illustrated by participant quotes:

- Knowing self as a person and leader: 'Learnt change starts with me' (C1, P4); 'I need to be more open minded and accepting/l need to listen to others'. (C1, P7); "The <programme> has made me realise that change starts with me. It has widened my perspective about the use of networking and its importance in striving to improve patient care and to improve one's enthusiasm in service delivery in primary care.' (C2, P9).

- Learning for self and enabling others: 'I have resilience, I can implement support change and develop others. (C1, P8)

- My relationships with others: 'I like seeing people achieve their potential'.(C1, P11) "It has helped me lead my clinical team and improve their morale. It has made me a stronger, more effective and interactive leader. We have a happier work place culture and are more dynamic. I also have a better work ethic and better time management.' $(\mathrm{C} 2, \mathrm{P} 4)$

Participants reported having an increased self-confidence, having experienced the opportunity to develop their leadership skills and put these into practice to develop their teams and lead changes in practice successfully.

They experienced a sense of personal growth through reflection and learning about self and reported being more motivated and excited about their work. Being able to learn more theory about leadership, and test this learning in the workplace had enabled them to understand more about how to lead with confidence amid NHS changes. The nature of this learning is illustrated in Table II by quotes drawn from the reflective reviews completed by participants and framed 
by the leadership journey synthesised from the final analysis. The impact of the programme on individual participants and their leadership practice is summarised in the first three levels of the leadership journey continuum.

\section{$<$ Insert Table II A Continuum of leadership Impact>}

The impact themes describing self as a leader were linked to three programme strategies: 1) recognition of participants' role in developing their team, 2) networking and supporting each other, and, 3) using tools to enable change.

Conceptual understanding of leadership across the individual participants' journey is demonstrated from collective analysis of data using the values clarification tool (Table I, method 1), thematically analysed to populate the co-created leadership framework (Table III). Collective themes identified key facets of leadership at individual and team level as a basis for deeper understanding. These themes acknowledged:

- the enablers needed to support their leadership development;

- how good leadership would be recognised;

- the consequences and outcomes of good leadership for themselves, across their teams and services. i.e. the potential impact.

During the programme this framework was revisited to capture ongoing learning. At the midpoint participants were asked to reflect on whether there were any elements missing or gaps identified. Points added appear in Table II in italics. The value of shared ownership, using the strengths of the team as collective leaders, as well as team stability and positive feedback from CCGs were recognised and therefore embellished the framework mid- programme based on reflective learning.

$<$ Insert Table III Leadership Impact Framework >

- Change starts with me and everyone can be involved in improving patient care, quality and service delivery.

- I have changed my approach to improve practice.

- I am a stronger, more effective and interactive leader to support, inspire and engage staff \& develop a happier workplace culture.

Question 2: What impact has the programme had on the workplace of the general practices involved from the perspective of the participant own reflections?

These findings are drawn from the data analysis themes from using methods 1, 3, 4,5 6 and 7 in Table I. They reflect the impact of the programme on participants' workplace teams at the beginning, mid-point and end of the programme.

The co-created vision statement for PCN leadership developed through the Values Clarification exercise (method 1) across the 2 cohorts, identified that the overarching purpose was "to make things better for staff and patients to achieve improved health outcomes through engagement; support; listening; working as a team; ensuring mental well-being; and providing a safe environment for staff/team \& patients" (Table II). Team enablers were identified as having a shared vision with explicit purpose and values, role clarity and clear team objectives and expectations of each other. Understanding how to get the best out the diverse talents of team members were seen as important to enable PCN teams to take 
a flexible approach to change and development. Valuing team members, being open and flexible to change, and creating patterns of behaviour that would embed person centered values were all identified as important team enablers, to create a team learning culture with shared ownership and responsibility for improvement. Peer review, education and learning from each other and mistakes were seen as central attributes to continued team growth and development. The consequences of effective team leadership were identified by the participants as team stability, with empowered staff who can think for themselves, feel valued and work in happy, healthy workplace teams that celebrate success. These outcomes were related to workforce retention and effective high performing teams.

By the mid-point of the programme, the Claims, Concerns and Issues data collection tool (Guba and Lincoln 1989, Table I method 4) highlighted that participants in both cohorts had begun to think about the impact of the programme on their workplace teams. This was not surprising given that they had been participating in peer consulting sessions together and had undertaken the Belbin team assessment. In Cohort 1 participants had begun to learn about using the full skill set of the team to improve team work and learning from others about what works when managing change. Their concerns were how to manage change with limited resources and demonstrating impact in a rapidly changing context, understanding how to access strategies that could enhance team functioning. The $\mathrm{CCls}$ tool enabled participants to co-create an action plan to identify what actions they could take together to address their concerns, thereby empowering them to take a collective leadership approach in their own workplaces. The strategies that were most valued by participants included using:

i) dedicated time in team meetings to identify the individual and collective strengths and interests of their team in their workplace;

ii) appreciative inquiry tools to enable them to focus on what matters most to members of the team, building on and celebrating success which included 360degree feedback from their team to highlight individual and collective strengths;

iii) quality improvement huddles to enable the team to focus in real time on what is going well, key areas for quality improvement and collaborative action planning by the team to make key changes to practices;

iv) high challenge and high support matrix to enable them to understand the impact of giving and receiving feedback to each other;

v) a model of critical companionship (Titchen ) to access reflective support for their growth and development beyond the programme lifespan.

By the end of the programme, Cohort 1 participants identified that the programme had enabled them to learn about how to develop their team through giving and receiving feedback, being open and honest with each other and understanding the impact that personality has on team functioning. They worked together on identifying strategies and tools that could be used in the workplace to engage and challenge staff, as well as thinking about how to use an appreciate feedback tools in practice. These strategies helped them to identify how to overcome key work-related issues related to time constraints, workload, keeping up to date with changes, and how to engage and deal with challenging colleagues. By the end of the programme they reported additional benefits such as networking more widely and using quality improvement huddles to focus team learning and reflection in their workplaces. Participants were focused on how to maintain momentum in their workplaces, continue learning and development, and demonstrate impact.

<Insert Table IV Summary of Claims Concerns and Issues related to teams> 
Cohort 2 participants did not complete an end-point $\mathrm{CCl}$ activity because of changes in programme facilitator personnel. However, at the mid-point of the programme, participants identified that they had been able to gain more insight into the impact of team personality on teamwork and functioning and how to get the best out of others in their team. They used similar strategies as cohort 1 to try out in their workplaces, how to motivate, engage and empower staff. Their reflections at the end of the programme were picked up by the reflective review (Table I!, method 5).

The reflective review (Table II) summarises the experiences of participants across the two cohorts in Level 3-5 of the leadership continuum.

3. I am a stronger more effective and interactive leader to support, inspire and engage staff \& develop a happier workplace culture: 'It helped to learn about how personalities differ and need to understand to ensure teams work more effectively and what is change, why needed and how to drive it and bringing change in culture' (C2, P9).

'I have the tools to inspire and motivate staff to continue to grow as a team and to effect the changes we would like to bring to the surgery' (C1, P3).

4. I, with team members manage change effectively using what I have learnt: 'Managing change effectively with transparency utilising new ideas and embedding them into and emerging culture from two practices that merged' (C1, P6).

5. With team members achieve a positive culture through new ways of working: 'Positive culture. Happy, stable team. Good communication between team members' (C2, P3).

The daily programme summary evaluations identified that the programme had afforded participants in both cohorts, time out of everyday practice providing the space to reflect and to think differently, trying out new tools and strategies in their workplaces in between sessions. Finding time and cover in the workplace was identified as a challenge for a couple of participants and may account for four participants failing to complete the programme in cohort 2.

Triangulation of data analysed (methods $1,3,4,5,6,7$ ) highlighted three specific themes of impact on their teams and practices, the importance of:

- collaborating with others, whether that is one's own team, other practices, the CCG, or networking to draw on others experiences and learning;

- multi-disciplinary team working \& learning and the impact leadership has on how staff experience the culture. This was seen through using skills learnt to engage their teams, inspire and support them, enable others to make decisions, celebrate achievements, learn from each other and recognising this impacts on staff motivation, morale and subsequently retention;

- a more explicit and specific sense of purpose through improving specific aims and objectives of the practice, having a focused purpose in their project. This insight was underpinned by the recognition that improving patient care is a powerful motivator and change can be very positive on a small scale. Also, that quality was everyone's business and it was better to try and fail than never try at all.

The focus on collaborative working is a noted strong feature.

At the end of the programme, participants in both cohorts were required to present a collaborative team project to commissioners to identify how the programme had enabled them 
466 to make planned improvements or innovations in their services. Examples of innovative 467 projects included:

- Developing a Triage Appointments Service (cohort 1)

- Telephone hub project (cohort 1)

- Social prescribing initiative for young mums, (Cohort 1)

- Physio support network in practice (cohort 1)

- Reducing Did Not Attend appointments (cohort 1)

- Community dermatology pathway (cohort 2)

- Identifying AF using alivecor in practice (cohort 2)

- Training and Peer Support Network for Primary Care Network Pharmacists in Medway and Swale (cohort 2)

- A blood donor awareness project (cohort 2)

Participants reflective reviews of the impact on their patients and communities (Level 7 of the leadership continuum Table II) identified the following benefits:

480 'Increased understanding of the patient journey - better care, improved service delivery, 481 more effective quality assurance' (C1, P5)

'Patients continue to improve surgery - involving patients in design and transformation'. (C2, P5)

'Modern up to date ideas and seeing the practice up there and doing it! The patients like to say, "My practice do this". (C1, P2)

Evidence of impact was seen as reductions in the number of patient complaints, and a greater ability to demonstrate the results of improvements to patients.

The programme leads, identified that following completion of the programme a range of impacts had been reported to them which had led to workplace promotions and funding of new services as follows:

- 2 GPs went on to take up a GP partnership following attending the programme.

- 1 Assistant Practice Manager was promoted to Practice Manager.

- 1 pharmacist as part of his project set up a community pharmacy peer support network (funded project by the North Kent Training Hub).

- 1 nurse became a lead practice nurse and Community Education Facilitator lead.

- $1 \mathrm{GP}$ progressed a project for Dermatology provision across North Kent with a primary care Dermatology Service (on hold due to COVID).

- $1 \mathrm{GP}$ took on a leadership role at the local GP Federation.

- 2 Practice Managers now have leadership positions in Primary Care Networks.

Question 3: What learning and development processes have been influential on the leadership strategies used by participants in the workplace to demonstrate impact?

Analysis of daily evaluations completed during the programme combined with data from the Claims, Concerns and Issues activity (Guba and Lincoln, 1989, Table 1 method 4), the reflective review and final project presentation (Table I, methods 3-7) indicated that there were a number of influential learning strategies contributing to the impact. This section of the findings links data derived from perceptions of the participants that connect four influential strategies to achieving impact. 
509 At the beginning of the programme, day 1 and 2 evaluation of learning across both cohorts 510 indicated a number of helpful learning strategies (Box VI).

511 <nsert Box V: Daily Evaluation Summary for Cohort 1 and 2 at beginning of the programme>

512 The approaches considered most helpful in the first sessions continued to be influential, 513 summarised here by participants in their daily evaluations as: "Peer consulting, reflecting and 514 learning how to do this"; "Undertaking MIRO assessment to understand who I am"; 515 "Discussion on claims, concerns and issues and how to structure meetings differently"; 516 "Unpicking enablers, attributes and consequences of leadership including vision and 517 transformational leadership to think about impact"; "Networking and learning with others 518 experiencing similar situations"; "Discussing organisational culture"; "Learning new tools and 519 approaches to obtain feedback"; "Being challenged by different ideas and understanding the 520 areas I need to change".

521 Table II leadership continuum 5 identifies participant summaries of impact. Overall one 522 participant identified that the learning strategies had helped to create "Happier empowered 523 staff = better patient experience = Better service". $(\mathrm{C} 2, \mathrm{P} 6)$

524 Peer consulting sessions created a safe space for individuals to "deconstruct general 525 practice", discuss a workplace issue and receive a multi-professional view of the problem. The 526 opportunity to take turns in facilitating these groups on the programme enabled them to gain 527 skills in using this tool back at their place of work. Creating reflective time away from the front 528 line and collaborative problem solving was a successful strategy for accelerating the future of 529 multi-professional working in primary care teams. Shared learning across professional groups 530 was highly valued, as well as helping to reduce the sense of isolation and working alone. 531 Participants reported this strategy helped them work on themselves as leaders, develop 532 others' effectiveness, as well as tackling difficult conversations. This was complemented by 533 enabling participants to undertake a MiRO psychometric assessment designed to help 534 individuals gain more self-awareness and in turn, enable their teams to perform better and 535 feel happier. MiRO generates a report containing graphic information and general attributes 536 regarding each individual team member, some general attributes of the team as a whole, a 537 description of some of the possible conflicts or creative tensions within the team, and 538 information pertaining to communication style, decision making style, relationship building 539 style and dealing with change. Exploration of the interrelationships between workplace values, 540 culture and leadership also helped participants to reflect on their own workplace culture, how 541 to deal with challenging behaviours and situations, and how to offer high support and high 542 challenge, to improve feedback within teams and enhance team performance and underpin 543 quality improvements.

Secondly, participants identified that using quality improvement tools and skills in practice for example, quality improvement huddles (NHS Improvement, 2019), and Claims, Concerns and Issues (CCls) (Guba and Lincoln, 1989), were really helpful. CCls enabled them to structure their team meetings more effectively and collaboratively action plan to solve workplace issues in real time with a collective sense of responsibility.

Learning how to network, and present alongside colleagues from other practices experiencing similar workplace issues was a powerful force for learning. Finally, learning how to learn about 553 personal impact using the leadership impact framework enabled participants to unpick the 
554 enablers, attributes and consequences of leadership, reflect on their own leadership style and 555 approach, their team and what they were trying to achieve.

556 In summary, there is evidence that the programme increases self-awareness about how 557 personal characteristics impact on participants' leadership roles and how emotional 558 intelligence contributes to building effective relationships, communication and learning at both 559 an individual and collective level. These themes arising from knowing self are linked to how 560 participants are beginning to work as leaders in the contexts of their teams and practices, 561 using tools for change and the skills of peer consulting and networking required to support and 562 develop people.

563 Whilst taking time out of clinical practice was challenging the positive outcome of this activity 564 meant that some participants reported that their teams were more engaged as a result. 565 Indeed, one participant from cohort 2 in their reflective review (Level 5 Leadership Continuum) 566 reported that the 'Practice would have fallen down if we hadn't done this course and learned 567 skills for staff engagement right up to project management' (C2, P10).

\section{Discussion}

569 There are two key strengths of this work. The first is its innovative approach to leadership 570 development which focuses on the journey of transformation for individual practitioners in 571 order to develop person-centred, safe and effective workplace cultures. The continuum of 572 impact created with participants through analysis of the reflective review data offers insight 573 into the journey of transformation from recognising that "change starts with me" (C2, P9), to 574 the impact on the team and workplace culture so that change can be more effectively managed 575 together (Table III). The enablers, attributes and consequences of participants' leadership 576 journeys identified in the co-created leadership impact framework (Table II), demonstrates that 577 participants have considered the impact of their development on self, their teams, patients and 578 wider service, and knew where they wanted to be. When these are viewed together it 579 represents a powerful illustration of leadership impact for the PCNs involved in the programme 580 at micro-, meso-, and macro-levels of the health care system.

The second is its approach to using the workplace as the main resource for learning, developing and improving both the quality of team relationships and workplace culture, and the impact on the services provided. In effect it has enabled participants to understand HOW to $\mathrm{DO}$ bottom up change collectively as evidenced by the reflective review comment in Box $\mathrm{V}$.

The programme has enabled participants to engage in collective leadership which embraces collective capability and endeavour when acting and learning together to shape the culture (NHS Improvement, 2019; Sharp, 2018; West et al., 2014). This is illustrated in Table II where the consequences of collective leadership are identified as effective high performing teams with shared ownership, delivering on their aims and objectives and demonstrating an ongoing commitment to productivity, innovation and adaptability (Manley et al., 2020; Cardiff et al., 2020).

The use of practice development methodology combined with concepts of transformational 595 clinical leadership offers a positive pathway to enabling and growing self-awareness, 596 empowerment, teamwork, and shared values in the workplace (Manley et al., 2016). These 
597 were important consequences identified by participants at both individual and team level 598 (Table II) as well as in Levels 1-3 of the leadership impact continuum (Table III). Similar 599 findings are echoed by Akhtar et al., (2016) who report that clinical leadership embracing 600 transformational and other collective leadership approaches is a key enabler for developing 601 effective workplace cultures at the micro-systems level. Practice development provides a key 602 methodology for embedding ways of working that are collaborative, inclusive and participatory 603 and celebratory.

604 The peer consulting model was a powerful strategy that helped to facilitate the development 605 of authentic, caring and appreciative relationships amongst participants, as well as enabling 606 participants from different professional roles to see and appreciate the inner potential in others, 607 drawing on their skills and talents in order to solve practice issues collectively. This inclusive 608 collective, shared and distributive leadership helps not only to improve self-awareness and 609 confidence, but also to create healthy teams who actively learn, engage, reflect and adapt and 610 are committed to improving practice through creativity and innovation in the workplace (Manley 611 et al., 2016; NHS Improvement, 2019; Stodd, 2016; Akhtar et al., 2016; Prentice, 2015; 612 Sherman and Pross, 2010; Coleman, 2013; Karimi et al., 2017; Taylor ,2014; Schwartz et al. 613 2011; Dewar et al., 2017; Dewar and Cook, 2014; Kings Fund, 2011; NHS Improvement, 614 2019b; Royal College of Speech and Language Therapists, 2018; Manley and Titchen, 2016; 615 Manley et al., 2019b). This approach also helps to improve staff wellbeing, morale and 616 satisfaction as well as improving retention (Manley et al., 2019b) as evidenced by the 617 outcomes identified in Table II. Opportunities to develop a shared understanding in teams 618 about what colleagues' priorities, values, beliefs and interests are, helps individuals and the 619 wider team to get energy from each other, and navigate risks and harness the learning that 620 comes from disappointments as well as success (Manley et al., 2019b). This was evident in 621 the quality of the projects presented to the commissioners at the end of the programme and 622 in the reflective comments from participants from their collective learning experiences.

623 Whilst participants were challenged by the activity of co-creating a shared purpose framework 624 to measure leadership impact at the start of the programme, it facilitated collaboration, 625 inclusion and participation principles early on and enabled focus on shared values and ways 626 of working together, an essential part of developing effective workplace cultures in the 627 workplace. In addition to being used as a powerful self-assessment tool throughout the 628 programme, it also helped practitioners to think about the systems for learning, development, 629 research, innovation and evaluation that needed to be established in their own practices and 630 everyday activity. Attending to culture at the micro-systems level is central to developing 631 workplaces that are safe and effective (Manley et al., 2019a), that prioritise learning to support 632 quality, person centered relationships and the wellbeing of providers and recipients of care. 633 West et al's. $(2014,2015)$ research into team effectiveness shows that strategies that enable 634 time away from the workplace to engage in reflexive activities is a key ingredient to enhancing 635 team effectiveness and performance.

636 This programme has the potential to be scaled nationally across the UK to support the 637 integration agendas of Integrated Care Services, to optimise the potential of PCNs to 638 collectively lead innovations in service integration and improvement. Attending to the 639 collective leadership skills of PCN teams as opposed to PCN leaders alone, could empower 640 whole teams to drive the speed of change to adapt to rapidly changing contexts and meet the 641 needs of local populations particularly dealing with as yet unknown issues such as the impact 
642 of Long- COVID on the health of communities. The programme easily lends itself to be 643 adapted to a digital learning platform that could be scaled nationally and internationally. 644 Longer term impact evaluation would be needed to demonstrate the wider system impacts for 645 PCN teams in the medium term.

\section{$646 \quad$ Limitations}

647 Firstly, the study methods focused on using practice development methodology and 648 experience-based co-design so that participants were using methods that would have direct 649 relevance and usefulness to improving their workplaces and team leadership. We would 650 recommend strengthening the longitudinal evaluation of the programme to determine how 651 sustainable the learning has been on PCN leaders and teams over time.

652 Secondly, the programme has been run with only two cohorts of PCN practitioners to date but 653 has the potential to be developed as an online programme with broader national and 654 international reach. The evaluation highlights that the programme could be strengthened 655 further by starting off with using the CCls at the beginning of participants' leadership journey 656 and taking a more incremental approach to developing the leadership impact framework. In 657 addition, participants highlighted that it would be helpful to consider how some of the tools 658 introduced early on could be used earlier in participants' own practice settings as well as with 659 the projects, including the development of key objectives against which improvement can be 660 measured. Participants initially wanted more traditional 'chalk and talk' lectures which made 661 it challenging at first, so guidance on the approach is recommended for the future to prepare 662 participants in advance of commencing the programme.

663

664

665

666

667

668

669

670

671

672

673

674

675

676

677

678

679

680

681

682

683

684

\section{Conclusions}

Primary care networks need to increase the engagement of GP practices and wider primary care teams, and strengthen their leadership and management, to become firmly established to meet the challenges ahead. Transforming the workforce to achieve the future challenges of $21^{\text {st }}$ century health care is a key enabler for supporting systems integration. This requires in itself a radical transformation in patterns of thinking and an approach that builds on collective leadership to grow social capital in PCNs. Systems leadership skills will be vital if silos and boundaries are to be dismantled (Manley and Jackson, 2020). The strong focus on values of people-centered approaches, safety, and effectiveness means that working with values to guide decision making will be a crucial skillset. Much more investment in facilitation skills is needed to enable frontline teams to feel supported and empowered to contribute creatively to the solutions required. Inter-professional learning, practice, and leadership, as well as continuous professional development, are all pivotal to the delivery and evaluation of sustainable transformation across the health economy to impact on future new models of care with a foundation in person-centred values, relationships, and shared decision making.

This programme demonstrates that building positive team relationships as well as individual and team leadership capacity and capability in a safe environment has enabled participants to develop their individual and collective confidence as leaders of teams and services. It has supported the development of participants' self-awareness and emotional intelligence, practising transformational leadership skills to engage and inspire their teams through collaboration, inclusion and participation. Becoming facilitators and enablers of others' effectiveness has helped participants to draw on their own workplaces as the main resource 
685 for learning, development and improvement in a collective effort to enhance the quality of 686 services provided. It offers great potential to support the development of other PCN teams 687 around the UK and more broadly internationally in place-based health care systems. There is 688 great interest in commissioning an expansion of the programme in a number of different 689 regions in England which provides scope for scaling the work to support the Integrated Care 690 System infrastructure to deliver the NHS Long Term Plan (2019) objectives for integrated 691 health and social care service delivery focused around localities to meet citizen and population 692 health needs.

693 The potential long-term benefits of the PCN Leadership programme are summarised in Figure 694 I. Implications for networks include:

- The importance of taking a multidisciplinary approach to leadership development across networks.

697

698

699

700

701

702

703

704

705

706

707

708

- Using co-created approaches with staff and stakeholders to embed and sustain change.

- Strengthening the quality of learning cultures across all settings for all staff.

- Increasing critical mass of skilled facilitators at every level of the system to enable the workplace to be the main resource for learning, developing and improving

- Ensuring that PCN leads have the skill set required for clinical systems leadership to embrace a collective leadership approach and the transformational leadership behaviours required.

- Increasing leadership resilience and reducing burnout by moving away from more hierarchical leadership styles.

- Energising and inspiring allied health care professionals and younger General Practitioners coming through the system to take on leadership roles.

$<$ Insert Figure I: Potential Long-Term Benefits of the PCN leadership programme> 


\section{References}

711 Akhtar M., Casha, J.N., Ronder J. et al.(2016). 'Leading the health service into the future: 712 transforming the NHS through transforming ourselves'. International Journal of Practice 713 Development, Vol.6, No. 2, Article 5 https://doi.org/10.19043/ipdj.62.005.

714 Cardiff, S., Sanders, K., Webster, J., Manley, K. (2020). 'Guiding lights for effective workplace 715 cultures that are also good places to work'. International Practice Development Journal, 716 November, https://www.fons.org/library/journal/volume10-issue2/article2v2

717 Coleman J. (2013). 'Six components of a great corporate culture'. Harvard Business Review 718 May 6. https://hbr.org/2013/05/six-components-of-culture.(accessed 28 December 2020).

719 Denney M., and Johnstone, A. (2019) .'Can general practice trainees engage with 720 leadership activities during their GP training placements? - An evaluation of an intervention 721 in South East Scotland.' Education Primary Care, Vol. 30, No. 2, pp.102722 109, DOI: 10.1080/14739879.2019.1566782

723 724

725

726

727

728

729

730

731

732

733

734

735

736

737

738

739

740

741

742

743

744

de Zulueta P.C. (2016). 'Developing compassionate leadership in health care: an integrative review.' Journal of Health Care Leadership, No.8, pp. 1-10.

Der Zijpp T., Niessen T., Eldh A., et al. (2016) 'A Bridge Over Turbulent Waters: Illustrating the Interaction Between Managerial Leaders and Facilitators When Implementing Research Evidence.' Worldviews in Evidence-Based Nursing, Vol. 3, No.1, pp. 25-31.

Economic and Social Research Council (ESRC). 'What is impact?' https://esrc.ukri.org/research/impact-toolkit/what-is-impact/ (accessed $28^{\text {th }}$ December 2020)

Dewar B., Barrie K., Sharp C., et al.( 2017). 'Implementation of a Complex Intervention to Support Leadership Development in Nursing Homes: A Multimethod Participatory Study'. Journal of Applied Gerontology, DOI: 10.1177/0733464817705957.

Dewar B., and Cook F. (2014). 'Developing compassion through a relationship centred leadership programme'. Nurse Education Today, Vol. 34, No. 9, pp.958-64.

Downey P., Waters M. (2005). 'Developing the primary healthcare team as a learning organisation: a new model using problem-based learning' . Education Primary Care 2005; Vol.16, pp. 301-7.

Guba E.G., Lincoln Y.S. (1989). 'Fourth Generation Evaluation.' London: Sage.1989.

Hana J., and Rudebeck C.E. (2011). 'Leadership in rural medicine: the organization on thin ice?' Scandinavian Journal of Primary Health Care, No. 29, pp. 122-128.

Hardy, S., Clarke, S., Frei, I.A., Morley, C., Odell, J., White, C ., and Wilson, V. (in press). 'A global manifesto for practice development: revisiting core principles' (Chapter 8). in Manley, Wilson, Øye (eds) International Practice Development in Health and Social Care. Wiley. Chichester. 
745 Middleton, R., Moroney, T., Jackson, C.,Germaine, R. (in press). 'Education models 746 embedding PD philosophy, values and impact - using the workplace as the main resource for 747 learning, developing and improving' (Chapter 6) in Manley, Wilson, Øye (eds) International 748 Practice Development in Health and Social Care. Wiley. Chichester

749 Johns C. (2005). 'Framing learning through reflection within Carper's fundamental ways of 750 knowing in nursing'. Journal of Advanced Nursing, Vol.22, No. 2, pp.226-234.

751 Karimi B., Mills J. ,Calvert E., et al. (2017). 'Transformational Leadership at point of care: 752 Approaches and outcomes in a long-term care setting.' Canadian Nursing Home, Vol. 28, No. 753 1, pp. 4-7.

754 King's Fund (2011). 'The Future of Leadership and Management in the NHS: No More 755 Heroes'. London: The King's Fund.

756 Kouzes J., and Posner, B. (2012). 'The Leadership Challenges How to Make Extraordinary 757 Things Happen in Organizations'. San Francisco, CA.

758 Manley K., Dewar B., Jackson C. et al. (2019b) 'Strengthening Nursing, Midwifery and Allied 759 Health Professional Leadership'. Unpublished Report. Burdett Trust for Nursing.

760 Manley K., \& Jackson C. (2020). 'The Venus model for integrating practitioner-led workforce 761 transformation and complex change across the health care system'. Journal of Clinical 762 Evaluation, 15 March, Vol. 26, No. 2, pp. 622-634.

763 Manley K., Jackson C., McKenzie C. (2019a). 'Microsystems culture change- a refined theory 764 for developing person centred, safe and effective workplaces based on strategies that embed 765 a safety culture.' International Journal of Practice Development, Vol.9, No. 2, pp. 34-141.

766

Manley K., Martin A., Jackson C., et al. (2016). 'Using systems thinking to identify workforce 768 enablers for a whole systems approach to urgent and emergency care delivery: a multiple 769 case study.' BMC Health Services Research, Vol.16, 368. https://doi.org/10.1186/s12913770 016-1616-y.

Manley K, and Titchen A. (2016). 'Facilitation Skills - The Catalyst For Increased 772 Effectiveness In Consultant Practice And Clinical Systems Leadership'. Educational Action 773 Research Journal, Vol. 24, No.2, pp. 1-24.

774 Marshall M., Holti R., Hartley J., et al. (2018). 'GP leadership in clinical commissioning 775 groups: a qualitative multi-case study approach across England'. British Journal of General 776 Practice, June, Vol. 68, No. 671, e427-e432.

777 National Institute for Health Research (2013). 'New Evidence of Leadership and 778 Management.' available at: www.nets.nihr.ac.uk/ programmes/hsdr (accessed 16 December 779 2020).

780 National Association of Primary Care. URL: https://napc.co.uk/primary-care-home/ 781 (accessed 19 October 2020). 
782 National Health Service (2019). The NHS Long term Plan

783 .https://www.longtermplan.nhs.uk/publication/nhs-long-term-plan/ (accessed March 2020).

784 NHS England (2014). 'Five Year Forward View.' https://www.england.nhs.uk/wp-

785 content/uploads/2014/10/5yfv-web.pdf. (accessed 2 December 2020)

NHS Improvement (2019). 'Implementing handovers and huddles: a framework for practice in maternity units' available at:

788 https://improvement.nhs.uk/documents/5038/Implementing_handovers_and_huddles.pdf 789 (accessed 1 May 2020).

NHS Improvement (2019b). 'Creating a Culture of Compassionate and Inclusive Leadership'. 791 [Online] Available at : https://improvement.nhs.uk/resources/culture-leadership/ (accessed 14 792 January 2019).

Nieuwboer M.S., van der Sande R., Marjolein A., et al. (2019). 'Clinical leadership and integrated primary care: A systematic literature review.' European Journal of General Practice. January, Vol. 25, No. 1, pp. 7-18, DOI: 10.1080/13814788.2018.1515907

O'Riordan C., and McDermott A. (2012). 'Clinical managers in the primary care sector: do the benefits stack up?' Journal of Health Organisation and Management, Vol. 26, pp.621-640.

Patton, M.Q. (1999). 'Enhancing the quality and credibility of qualitative analysis'. 799 Health Services Research, December, Vol. 34, No.,5 Pt 2, pp.1189-208. PMID: 800 10591279; PMCID: PMC1089059.

801 Prentice D. (2015). 'Enhancing Leadership skills for bedside RNS: Evaluation of a Leadership 802 programme'. Perspectives Vol. 38, No. 1, p. 17.

803 Royal College of Speech and Language Therapists (2018). 'Excellent AHP Leadership 804 Connections'. [Online] Available at :

805 https://www.rcslt.org/governments/docs/leadership_day_report [accessed 14 January 2019].

806 Schwartz D., Spencer T., Wilson B., et al. (2011). 'Transformational leadership: implications 807 for nursing leaders in facilities seeking magnet designation'. AORN Journal Vol. 93, No. 6, pp. 808 737-748.

809 Sharp C. (2018). 'Collective leadership: Where nothing is clear and everything keeps 810 changing. Exploring new Territories for Evaluation'. Workforce Scotland. [Online] available: at 811 http://tinyurl.com/y6vll2hp [accessed 11 March 2019].

812 Sherman R., and Pross E. (2010). 'Growing future nurse leaders to build and sustain 813 healthy work environments at the unit level' . The Online Journal of Issues in Nursing, Vol. 814 15, No. 1, Manuscript 1. DOI: 10.3912/OJIN.Vol15No01Man01

815 Simons G., and Woods M. (2015). 'How Confident are GP Trainers to Teach Clinical 816 Leadership?' Education Primary Care, Vol.26, No. 3, pp. 211-212. 
818 Smith, J.; Parkinson, S., Harshfield, A., Sidhu, M. (2020). 'Early evidence of the

819 development of primary care networks in England: a rapid evaluation study'. Southampton:

820 NIHR Health Services and Delivery Research Topic Report; 2020. DOI:

821 https://doi.org/10.3310/hsdr-tr-129678

822 Stodd J. (2016). 'The Social Leadership Handbook'. (2nd edition). California: Smashwords

823 Storey J., Holti R., Hartley J., et al. (2019). 'Devolving healthcare services redesign to local

824 clinical leaders: does it work in practice? ' Journal of Health Organisation and Management, 825 Vol. 33, No. 2, pp.188-203. doi:10.1108/JHOM-05-2018-0144.

826

827 Swanwick T., and Varnam, R. (2019). 'Leadership development and primary care. BMJ

828 Leader, 3, pp. 59-61.

829 Taylor L.D.L. (2014). 'Perioperative Leadership: Managing Change with Insights, Priorities, 830 and Tools.' AORN Journal, Vol. 100, No. 1, pp. 8-29.

831 The Kings Fund (2020). 'Primary Care Networks Explained'.

832 https://www.kingsfund.org.uk/publications/primary-care-networks-explained. (accessed $83323.12 .2020)$

834 Warfield, C. and Manley, K. (1990). 'Developing a new philosophy in the NDU'. Nursing 835 Standard, Vol. 4, No. 41. pp 27-30.

836 Watson, N. (2019). 'GP partnership review: final report.'

837 Available: www.gov.uk/government/publications/gp-partnership-review-final-

838 report [accessed 19 December 2020].

839 West M., Eckert R., Steward K,. et al. (2014). 'Developing collective leadership for health care'.

840 The King's Fund/Centre for Creative Leadership, London. Available at: 841 www.kingsfund.org.uk/sites/default/files/field/field_publication_file/developing-collective842 leadership-kingsfund- may14.pdf (accessed 6 November 2018).

843 West M., Armit K., Loewenthal L., et al. (2015). 'Leadership and Leadership Development in 844 Health Care: The Evidence Base.' Faculty of Medical Leadership and Management, London. 845 Available at: www.kingsfund.org.uk/sites/files/kf/field/field_publication_file/leadership846 leadership-development-health-care-feb-2015.pdf (accessed 6 November 2018). 


\title{
Change Starts with Me: An impact evaluation of a multiprofessional leadership programme to support Primary Care Networks in the South East of England
}

\author{
Jackson C, Manley K, Vibhuti M
}

\section{Box 1: Medway and Swale Multiprofessional PCN Leadership Programme Aims and Principles}

The programme aimed to develop the individual and collective leadership capacity and capability of PCN teams to transform services to meet local population health needs and support development of Integrated Care Services across the South East of England. Teams were provided with a

combination of personal, professional and business learning opportunities, with an emphasis on the mind-sets and behaviours associated with leading high performing multi-disciplinary teams, in general practice and within and across networks.

The principles of the programme were to:

- Build space for reflection, discussion with peers and senior leaders and practice.

- Making content, experiences and exercises as relevant to real work of leaders.

- Engaging different senses and emotions e.g. patient stories, video and hands on.

- Making sure the environment is receptive to the new skills and allows the practise of these skills.

- Recognise that leadership is a lifelong art like medicine, not a 5-day fix.

By the end of the programme delegates will be on the journey to:

- Being a strong adaptive leader

- System thinkers

- Agile learners

- Self-aware

- Comfortable leading through uncertainty 


\section{Box II: Medway and Swale Multiprofessional PCN Leadership Programme main learning and development processes}

- $\quad$ Each of the 8 days was based away from the clinical practice setting and covered topics such as the future of primary care, $21^{\text {st }}$ century leadership trends, organisational development, emotional intelligence, quality improvement methodology, coaching and mentoring skills as well as technology in healthcare and building resilience.

- Co-creating a shared direction and common purpose through developing a leadership impact framework as a reflective assessment tool to map their leadership journey and personal growth throughout the programme.

- Self-assessment of leadership confidence, styles and personalities within team contexts e.g. Kouzes and Posner Transformational Leadership Inventory (Kouzes and Posner, 2012); MiRO individual psychometric assessment (https://www.miro-assessment.com/) and Belbin team-based assessments (https://www.belbin.com/about/belbin-team-roles/).

- Using tools that can be used in the workplace to create a good culture and effective working e.g. Values Clarification (Warfield and Manley 1990); Claims, concern and issues (Guba and Lincoln; 1989).

- Learning how to facilitate change and collaboratively problem solve through 'Peer Consulting' sessions, which created a safe space for individuals to discuss a workplace issue and receive a multi-professional view of the problem through action learning.

- Pitching a collaborative project or idea designed with fellow participants, to clinical commissioners to demonstrate how their PCNs could provide improved services to meet population need.

- The opportunity to gain Masters level academic credits as an option should the participants wish to write up a reflective piece of their learnings. 


\section{Box III: Assumptions underpinning the approach to impact evaluation}

Using collaborative, inclusive and participative approach 'with participants' rather than 'on them' - drawing from the principles and values of practice development (Hardy et al., 2021) and experience-based co-design methodology (Manley et al., 2008) is more likely to achieve engagement and empowerment.

Supporting participants to co-create their own impact framework at the beginning of the programme, enables them to think deeply about and engage with developing a shared understanding of leadership and what they set out to achieve.

Exposing participants to tools that could be used within their own practice settings will positively impact on their practice through focusing on what matters to stakeholders.

Quality health care, defined as the triad of person-centred, safe and effective care, is dependent on effective workplace cultures and these are achieved through quality leadership (Manley and Jackson 2020; Manley et al. 2019).

Improving workplace cultures is a proxy for longer term health and staff impact gains, such as improved indicators of health and wellbeing, staff retention and system integration (Manley and Jackson 2020; Manley et al. 2019). 
Box IV: Levels of experience of measuring impact among participants - Illustration of themes and original data from analysis across fourpoint Likert scale drawn from Cognitive mapping for Cohort 1, Statement 3: I know how to evaluate my impact as a leader on both the staff and the service $(n=14)$. Numbers in bracket identifies anonymised participant identifier.

\begin{tabular}{|c|c|c|c|}
\hline -- & - & + & ++ \\
\hline $\begin{array}{l}\text { NO EXPERIENCE OF MEASURING } \\
\text { IMPACT do not have any experience } \\
\text { of measuring impact.(P 1) } \\
\text { 'At present I am nervous to evaluate } \\
\text { my impact as a leader '(P3) } \\
\text { 'I do hope to learn how to do } \\
\text { this.'(P4) } \\
\text { 'I understand how to evaluate but not } \\
\text { put into practice but plan to begin } \\
\text { taking the risks involved' (P8) }\end{array}$ & $\begin{array}{l}\text { 'NOT CONFIDENT IN MEASURING } \\
\text { IMPACT } \\
\text { As above' (P2) } \\
\text { 'I am not confident in evaluating my impact.' } \\
\text { (P5) } \\
\text { Feedback and outcomes of change by } \\
\text { methods used.'(P7) } \\
\text { I DON'T HAVE PERSONAL PROCESSES \& } \\
\text { SYSTEMS IN PLACE } \\
\text { 'I don't have personal processes of systems } \\
\text { in place to evaluate my impact on both staff } \\
\text { and service.'(P6) } \\
\text { I HAVE SOME IDEAS } \\
\text { 'I have some ideas as to how this might work } \\
\text { but have not put any of it into practice.' (P11) } \\
\text { 'I only measure on how my perception is of } \\
\text { this.'(P12) }\end{array}$ & $\begin{array}{l}\text { ACTIVELY ASK FOR FEEDBACK AND } \\
\text { MONITOR THIS } \\
\text { 'Ask for feedback, meet the staff and } \\
\text { patients, monitor progress with a project, } \\
\text { constant re-evaluation of what works or } \\
\text { not.' (P 13) } \\
\text { 'Quality outcomes (clinical)' (P 5) } \\
\text { Staff feel valued, included, have voice and } \\
\text { able to influence change.' (P 14) } \\
\text { HAVE THE FEEL BUT NOT THE } \\
\text { METRICS } \\
\text { 'I suppose so, but not the metrics - just the } \\
\text { 'feel'(P 13) }\end{array}$ & $\begin{array}{l}\text { HAVE DONE THIS BEFORE } \\
\text { THROUGH APPRAISALS } \\
\text { 'Have done it before and had } \\
\text { feedback on it and my own } \\
\text { appraisals.'(P 11) }\end{array}$ \\
\hline
\end{tabular}




\section{Box V: Daily Evaluation Summary for Cohort 1 and 2 at beginning of the programme}

\section{DAY $1 \& 2$ analysis of daily evaluations}

- Specifically learng about self and impact of self on others::

- Developing the facilitaiton skills, emotional intelligence, self awareness, listening skills and subseqentluy more cobfidence as a leader - the Peer consulting is assisting with this

- Working with own teams and developing their potential

- Understand the components of good team work - shared vision

- How to work with their own teams and draw on their diverse strengths

- How to structure meetings differently

- How to obtain feedback - learning new tools and approaches to obtain feedback and inform quality improvements

- Appreciating the contextual factors as well as personal factors that influence leadership impact 


\section{Box VI: Participant Response (C=Cohort, P=Participant Number)}

'Within the last 7 months this course has enabled me to develop my skills. I have been able to use the emotional intelligence with my team, plan on using peer consulting and the huddle to improve practice communication, problem solving, and empowering staff to solve some of their own

problems. In turn using some of the new techniques should improve staff satisfaction and hopefully improve retention.' (C1, P11) 
Table I: Impact Evaluation questions, data collection methods, analysis and triangulation outputs

\begin{tabular}{|c|c|c|c|c|}
\hline Question & Methods/ timepoint & Data Sets and analysis & Impact Insights & $\begin{array}{l}\text { Triangulation of } \\
\text { multiple data } \\
\text { sources }\end{array}$ \\
\hline $\begin{array}{l}\text { What impact has the } \\
\text { programme had on } \\
\text { individual } \\
\text { participants in their } \\
\text { leadership practice? } \\
\text { (Q1) } \\
\text { What impact has the } \\
\text { programme had on } \\
\text { the workplace of the } \\
\text { general practices } \\
\text { involved from the } \\
\text { perspective of the } \\
\text { participant own } \\
\text { reflections? (Q2) }\end{array}$ & $\begin{array}{l}\text { 1. Values clarification (Warfield and } \\
\text { Manley, 1990) generated qualitative } \\
\text { data from work groups about } \\
\text { leadership, its purpose, processes, } \\
\text { enablers and outcomes in session } 1 \\
\text { by research facilitator. } \\
\text { a. Revisiting and revising this } \\
\text { framework based on group } \\
\text { collective self-assessment } \\
\text { at programme mid-point } \\
\text { and end point. } \\
\text { 2. } \\
\text { Identification of individual hopes, } \\
\text { fears and expectations (cohort } 1 \text { ) } \\
\text { or top three leadership } \\
\text { opportunities, challenges, } \\
\text { successes and obstacles (cohort } \\
\text { 2) at the beginning of the } \\
\text { programme. } \\
\text { Self-assessment: } \\
\text { a) cognitive mapping against } \\
\text { three statements and Likert scale: } \\
\text { I feel I am effective in my role as } \\
\text { a leader, in that I make a } \\
\text { difference to both the staff I work } \\
\text { with and the service users } \\
\text { I am able to demonstrate my } \\
\text { impact as a leader on both the } \\
\text { staff and the service users' } \\
\text { experience } \\
\text { I know how to evaluate my } \\
\text { impact as a leader on both the } \\
\text { staff and the service } \\
\text { b) Kouzes and Posner leadership } \\
\text { inventory (2012) }\end{array}$ & $\begin{array}{l}\text { Qualitative data analysed thematically by participants } \\
\text { and mapped to a concept analysis framework } \\
\text { structured around the attributes, enablers and } \\
\text { consequences of leadership to enable collective } \\
\text { conceptual understanding of leadership at the } \\
\text { beginning of the programme. Synthesised across both } \\
\text { cohorts by research team (See Table ii) } \\
\text { Refinements of understanding made at mid-point and } \\
\text { end point based on collective self-assessment of } \\
\text { learning (See Table ii italics) } \\
\text { Qualitative data collected at the beginning of the } \\
\text { programme and thematically analysed by participant } \\
\text { groups under each heading - hopes, fears and } \\
\text { expectations. }\end{array}$ & $\begin{array}{l}\text { Collaborative understanding } \\
\text { about what leadership is, } \\
\text { leadership skills, enablers, } \\
\text { consequences including } \\
\text { potential impact on self, team, } \\
\text { workplace. } \\
\text { (See Table ii) } \\
\text { Learning about self and } \\
\text { leadership role and the factors } \\
\text { that affect these } \\
\text { (See Table ii) } \\
\text { What matters to participants at } \\
\text { the beginning of their } \\
\text { leadership journey }\end{array}$ & $\begin{array}{l}\text { Synthesised from } \\
\text { all data sets: } \\
\text { 1) Identification of } \\
\text { impact on } \\
\text { individual, } \\
\text { team, service } \\
\text { 2) The Leadership } \\
\text { Impact Journey } \\
\text { (Table iii) } \\
\text { 3) Identification of } \\
\text { the learning } \\
\text { and } \\
\text { development } \\
\text { strategies that } \\
\text { supported } \\
\text { leadership } \\
\text { journey }\end{array}$ \\
\hline
\end{tabular}




\begin{tabular}{|c|c|c|c|c|}
\hline $\begin{array}{l}\text { What learning and } \\
\text { development } \\
\text { processes have } \\
\text { been influential on } \\
\text { the leadership } \\
\text { strategies used by } \\
\text { participants in the } \\
\text { workplace to } \\
\text { demonstrate } \\
\text { impact?(Q3) }\end{array}$ & $\begin{array}{l}4 . \\
\\
5 .\end{array}$ & $\begin{array}{l}\text { Claims Concerns and Issues - a } \\
\text { stakeholder evaluation tool (Guba } \\
\text { and Lincoln, 1989) used mid } \\
\text { programme and end of programme } \\
\text { by research facilitator } \\
\text { Reflective Review tool (Johns, } \\
\text { 2005) focuses on synthesising } \\
\text { learning, impact and processes by } \\
\text { individual participants based on } \\
\text { own reflective data sources and } \\
\text { undertaken at the end of the } \\
\text { programme. Includes: } \\
\text { - hopes at beginning of } \\
\quad \text { programme } \\
\text { - learning themes over the } \\
\text { journey } \\
\text { enablers and inhibitors to } \\
\text { learning } \\
\text { consequences for self, team, } \\
\text { others } \\
\text { - } \quad \text { projected learning themes } \\
\text { statement for manager about } \\
\text { impact on culture } \\
\text { Review of project presentations, } \\
\text { PowerPoint and feedback notes at } \\
\text { the end of the programme to } \\
\text { commissioners } \\
\text { Daily written evaluation of each } \\
\text { study day completed by participants } \\
\text { to provide qualitative and } \\
\text { quantitative (Likert scale) data }\end{array}$ & $\begin{array}{l}\text { Documentary analysis to identify examples of impact } \\
\text { at each level -micro, meso, macro } \\
\text { Analysis of qualitative and quantitative data by } \\
\text { research team to identify themes and frequencies } \\
\text { from feedback about learning and development } \\
\text { strategies }\end{array}$ & $\begin{array}{l}\text { What matters to participants } \\
\text { (celebrations and concerns) } \\
\text { and the questions they are } \\
\text { asking themselves on their } \\
\text { leadership journey } \\
\text { Perceived insights to own self- } \\
\text { awareness, learning and } \\
\text { impact on self, team, } \\
\text { workplace about leadership } \\
\text { and its impact }\end{array}$ \\
\hline
\end{tabular}


Table II: A Continuum of leadership Impact across the leadership journey developed from data synthesis across all methods, illustrated with data from reflective reviews ( $C=$ cohort, $N=$ participant number)

\begin{tabular}{|c|c|}
\hline $\begin{array}{l}\text { LEVEL OF } \\
\text { CONTINUUM }\end{array}$ & PARTICIPANT INSIGHTS ARISING FROM REFLECTIVE REVIEWS \\
\hline $\begin{array}{l}\text { 1. CHANGE } \\
\text { STARTS WITH } \\
\text { ME and } \\
\text { everyone can be } \\
\text { involved in } \\
\text { improving patient } \\
\text { care, quality and } \\
\text { service delivery }\end{array}$ & $\begin{array}{l}\text { 'I am calmer and more resilient about tackling issues and trying new ways of working without being fearful of failure.' (C1, P8) } \\
\text { 'I recognise that quality is in everything we do. It isn't an added extra and patients' feedback is an untapped resource to help us develop an } \\
\text { effective service'. (C2, P4) } \\
\text { 'The Leadership Masterclass has made me realise that change starts with me. It has widened my perspective about the use of networking and } \\
\text { its importance in striving to improve patient care and to improve one's enthusiasm in service delivery in primary care.' (C2, P9) }\end{array}$ \\
\hline $\begin{array}{ll}\text { 2. I HAVE } \\
\text { CHANGED MY } \\
\text { APPROACH to } \\
\text { improve practice }\end{array}$ & $\begin{array}{l}\text { 'An understanding of different personality traits, peer review, making changes have changed my approach. In the workplace. I will aim to apply } \\
\text { and build on what I have learned to improve the practice.' }(\mathrm{C} 2, \mathrm{P} 3) \\
\text { 'I have spent my time on this course having an enlightening of my capabilities. I can see that I should be an enabler in the workplace to enthuse } \\
\text { others to make the surgery adopt and be more fit for purpose in a positive way.' (C1, P12) }\end{array}$ \\
\hline $\begin{array}{l}\text { 3. I AM A } \\
\text { STRONGER, } \\
\text { MORE } \\
\text { EFFECTIVE } \\
\text { AND } \\
\text { INTERACTIVE } \\
\text { LEADER to } \\
\text { support, inspire } \\
\text { and engage staff } \\
\text { \& develop a } \\
\text { happier } \\
\text { workplace culture }\end{array}$ & $\begin{array}{l}\text { 'It has helped me lead my clinical team and improve their morale. It has made me a stronger, more effective and interactive leader. We have a } \\
\text { happier work place culture and are more dynamic. I also have a better work ethic and better time management.' (C2, P4) } \\
\text { 'It helped to learn about how personalities differ and need to understand to ensure teams work more effectively and what is change, why needed } \\
\text { and how to drive it and bringing change in culture. ' (C2, P9) } \\
\text { 'By attending this course, I feel that I have grown in confidence and feel that I have the tools to inspire and motivate staff to continue to grow as a } \\
\text { team and to effect the changes we would like to bring to the surgery.' (C1, P3) } \\
\text { 'The course has taught me skills which I have been able to put into practice to engage staff in the vision of the practice.' (C1, P11) }\end{array}$ \\
\hline $\begin{array}{l}\text { 4. I with team } \\
\text { members } \\
\text { MANAGE } \\
\text { CHANGE } \\
\text { EFFECTIVELY }\end{array}$ & $\begin{array}{l}\text { 'Managing change effectively with transparency utilising new ideas and embedding them into and emerging culture from two practices that } \\
\text { merged.' (C1 P6) } \\
\text { 'Within the last } 7 \text { months this course has enabled me to develop my skills. I have been able to use the emotional intelligence with my team, plan } \\
\text { on using peer consulting and the huddle to improve practice communication, problem solving, and empowering staff to solve some of their own } \\
\text { problems. In turn using some of the new techniques should improve staff satisfaction and hopefully improve retention.' (C1, P11) }\end{array}$ \\
\hline
\end{tabular}


using what I have

learnt

5. With team

members

ACHIEVE A

POSITIVE

CULTURE

through new

ways of working

6. INTRODUCING INNOVATIONS

that positively

impact on

practice

7. IMPACT ON

PATIENTS/

COMMUNITIES
'Positive culture. Happy, stable team. Good communication between team members.'(C2, P3)

'Happier empowered staff $=$ better patient experience $=$ Better service'. $(C 2, P 6)$

'Reflective review in action with interactions with colleagues ' (C1, P8)

'Implementing huddles to improve support and team work' (C2, P9)

'Streamlining workload CCls embedded in practices' (C1 P7)

'Collaborative practice effort solving demand on practice' (C1, P12)

'Can't underestimate course for supporting service redesign' (C1, P13)

'Practice would have fallen down if we hadn't done course and learned skills for staff engagement right up to project management ' $(C 2, \mathrm{P} 10)$

- Telephony platform for GP practice gained 5 year forward funding (C2, P 4)

- Funding from CCG to support project plan successful outcome $(C 1,12)$

- Using force field analysis tools - New economics foundation (C1, P10)

- Clinical lead of CCG governing board looking forward to seeing more projects and funding applications (C2, P4)

- Projects clearly identify accurately issues in Medway so will help with solutions (C2, P12)

'Increased understanding of the patient journey - better care, improved service delivery, more effective quality assurance' (C1, P5)

'Plans to initiate social prescribing scheme for benefit of patients suffering from social isolation. Benefiting primary care as well as wider NHS'(C1, P8)

'We are able to demonstrate our results - positive' (C2, P9)

'We have less complaints from patients. (C2, P4)

'Patients continue to improve surgery - involving patients in design and transformation'. (C2, P5)

"Modern up to date ideas and seeing the practice up there and doing it! The patients like to say, "My practice do this". (C1, P2) 
Table III: Leadership Impact Framework based on participants understanding of leadership, its enablers and consequences at the beginning of the programme and refined midpoint. Derived from values clarification and thematic analysis by participants (Items in italics added mid programme

\section{by participants)} To support effective leadership Individual enablers:

- Core values: courage, compassion support

- $\quad$ Core attributes: humour, self-belief

- No blame attitude \& an 'open door'

Team/Practice Enablers

- $\quad$ Shared vision, explicit purpose \& values

- Multi-disciplinary diverse team:

- Understand others contributions \& own limitations

- $\quad$ Clear expectations \& role clarity

- Valued, flexible staff open to new ideas

- Tools and skills

- Recognition of key stakeholders as patients, staff, regulators, commissioners

- $\quad$ Agreed team objectives

- $\quad$ Patterns of thinking that enable values to be embedded

\section{Organisational/Systems Enablers}

- Enabling organisational culture

- Good physical environment

- Resources and finance

\section{ATTRIBUTES}

What would be happening in effective leadership? Individual Leadership Activities and Behaviours Observed or Experienced

Living core values and leading by example

$\checkmark \quad$ Being brave, risk taking, persevering

$\checkmark$ Building relationships, trust and a positive environment towards a shared purpose

$\checkmark \quad$ Valuing staff team members

$\checkmark \quad$ Building an open honest and transparent culture

$\checkmark$ Supporting, listening to staff \& attending to wellbeing $\checkmark$ Inspiring teams to work together, celebrating

\section{Team/Practice Processes:}

- Team/Practice work collaboratively and cohesively as an engaged team:

$\checkmark \quad$ towards a shared vision using joined-up thinking, consistency and clarity

$\checkmark \quad$ sharing best practice for quality care

$\checkmark$ embracing change, generating ideas, innovation and being adaptable

$\checkmark$ communication, planning, explicit aims and objectives

$\checkmark$ Using internal and external engagement strategies for feedback from all stakeholders

- Team functions in an inclusive, organised/efficient and nonhierarchical manner with shared ownership and uses strengths of team members

- Continued team growth and development through participation

$\checkmark \quad$ peer review \& developing insights,

$\checkmark$ education

$\checkmark \quad$ learning from each other and learning from mistakes

Experience of Patients, Visitors, Stakeholders

- Patients, Visitors, Stakeholders experience a culture of positivity, that is empathetic, happy, calm and stable

\section{CONSEQUENCES \& OUTCOMES OF EFFECTIVE} LEADERSHIP

\section{Individual Leadership Outcomes}

- Become more self-aware

- Increased confidence as a leader

- Know how to inspire and motivate

- Using different tools to support leadership role

- Become a more effective leader

- Know how to develop an effective culture

Team/Practice Focused Outcomes

Staff:

- Empowered staff who can think for themselves

- Team is stable, happy and feels valued

- Staff experience good morale, growth and success and good health

- Workforce, retention, less complaints from staff

Team Outcomes: effective high performing team

- Shared ownership

- Delivers aims and objectives

- Demonstrates on-going productivity, innovation and adaptability

Patient \& Service Outcomes

- Good feedback from patients, patient satisfaction, low level of complaints

- Quality, safe and effective clinical care experienced

- Improvement in the lives of others

- Measurable outcomes: QOF, CQC, results reward, profit

- Positive CCG Feedback 
Table IV - Summary of Themes arising from Claims, Concerns and Issues Identified at the Midpoint and End of the Programme ( $\mathrm{N}=$ number of participant responses per theme)

\begin{tabular}{|c|c|c|c|c|c|c|}
\hline \multirow[t]{2}{*}{ Cohort } & \multicolumn{2}{|l|}{ Claims } & \multicolumn{2}{|l|}{ Concerns } & \multicolumn{2}{|l|}{ Issues } \\
\hline & Mid-Point & End of Programme & Mid-Point & $\begin{array}{l}\text { End of } \\
\text { Programme }\end{array}$ & Mid-Point & $\begin{array}{l}\text { End of } \\
\text { Programme }\end{array}$ \\
\hline Cohort 1 & $\begin{array}{l}\text { Using the full } \\
\text { skillset of the MDT } \\
\text { to improve } \\
\text { teamwork (6) } \\
\text { - } \quad \text { Learning form } \\
\text { others, } \\
\text { understanding what } \\
\text { works when } \\
\text { managing change } \\
\text { (8) }\end{array}$ & $\begin{array}{ll}\text { - } & \text { Inspire and be a better } \\
\text { leader in practice and } \\
\text { education - reflecting } \\
\text { constantly (8) } \\
\text { - } \quad \text { Developing staff (8) } \\
\text { - } \quad \text { Huddles (4) } \\
\text { - } \quad \text { Being open, honest } \\
\text { and listen, saying } \\
\text { things in ways that } \\
\text { can be heard (6) } \\
\text { Giving difficult } \\
\text { feedback using } \\
\text { emotional intelligence } \\
\text { (5) } \\
\text { Understanding } \\
\text { personality - mine and } \\
\text { others (6) } \\
\text { Wealth of learning on } \\
\text { leadership (9) } \\
\text { Understanding } \\
\text { successful change } \\
\text { (10) } \\
\text { How to network (8) }\end{array}$ & $\begin{array}{l}\text { Making change } \\
\text { with limited time } \\
\text { \& resources (8) } \\
\text { Showing } \\
\text { impact within } \\
\text { changing context } \\
\text { (6) } \\
\text { - Accessing and } \\
\text { using feedback } \\
(6)\end{array}$ & $\begin{array}{l}\text { Bigger } \\
\text { Picture, } \\
\text { keeping up } \\
\text { to date with } \\
\text { changes } \\
\text { (8) } \\
\text { Staying } \\
\text { fresh and } \\
\text { maintaining } \\
\text { momentum, } \\
\text { learning } \\
\text { and } \\
\text { progress } \\
\text { (6) }\end{array}$ & $\begin{array}{l}\text { - How do I stay fresh } \\
\text { and maintain } \\
\text { momentum, } \\
\text { learning and } \\
\text { progress? (8) } \\
\text { How do I continue } \\
\text { to use the tools, } \\
\text { and continue } \\
\text { learning and taking } \\
\text { potential } \\
\text { opportunities? (6) } \\
\text { Financial \& Other } \\
\text { Resources (4) }\end{array}$ & $\begin{array}{l}\text { Remembering } \\
\text { tools, } \\
\text { continuing } \\
\text { with learning } \\
\text { and taking } \\
\text { potential } \\
\text { opportunities } \\
\text { (8) } \\
\text { Financial \& } \\
\text { Other } \\
\text { Resources (6) }\end{array}$ \\
\hline Cohort 2 & $\begin{array}{l}\text { - Learning how to get } \\
\text { the best out of } \\
\text { others (8) } \\
\text { - I can identify the } \\
\text { personality types of } \\
\text { people in my team } \\
\text { (8) }\end{array}$ & & $\begin{array}{l}\text { How to empower } \\
\text { others (8) } \\
\text { How to engage } \\
\text { others when } \\
\text { obstacles } \\
\text { because team } \\
\text { members not } \\
\text { wanting to } \\
\text { participate (8) }\end{array}$ & & $\begin{array}{l}\text { - How is the } \\
\text { programme making } \\
\text { a difference? (6) } \\
\text { - Where does it fit in? } \\
\text { (4) }\end{array}$ & \\
\hline
\end{tabular}


Figure I: Potential Benefits of the PCN Leadership Programme for the wider health and social care system to deliver the NHS Long Term Plan (2019) adapted from Malby, R. et al. (2020). Leading Primary Care Networks and Collaborations'.

https://www.Isbu.ac.uk/_data/assets/pdf_file/0011/139484/Learning-Primary-Care-Networks-and-Collabs-23.01.20.pdf

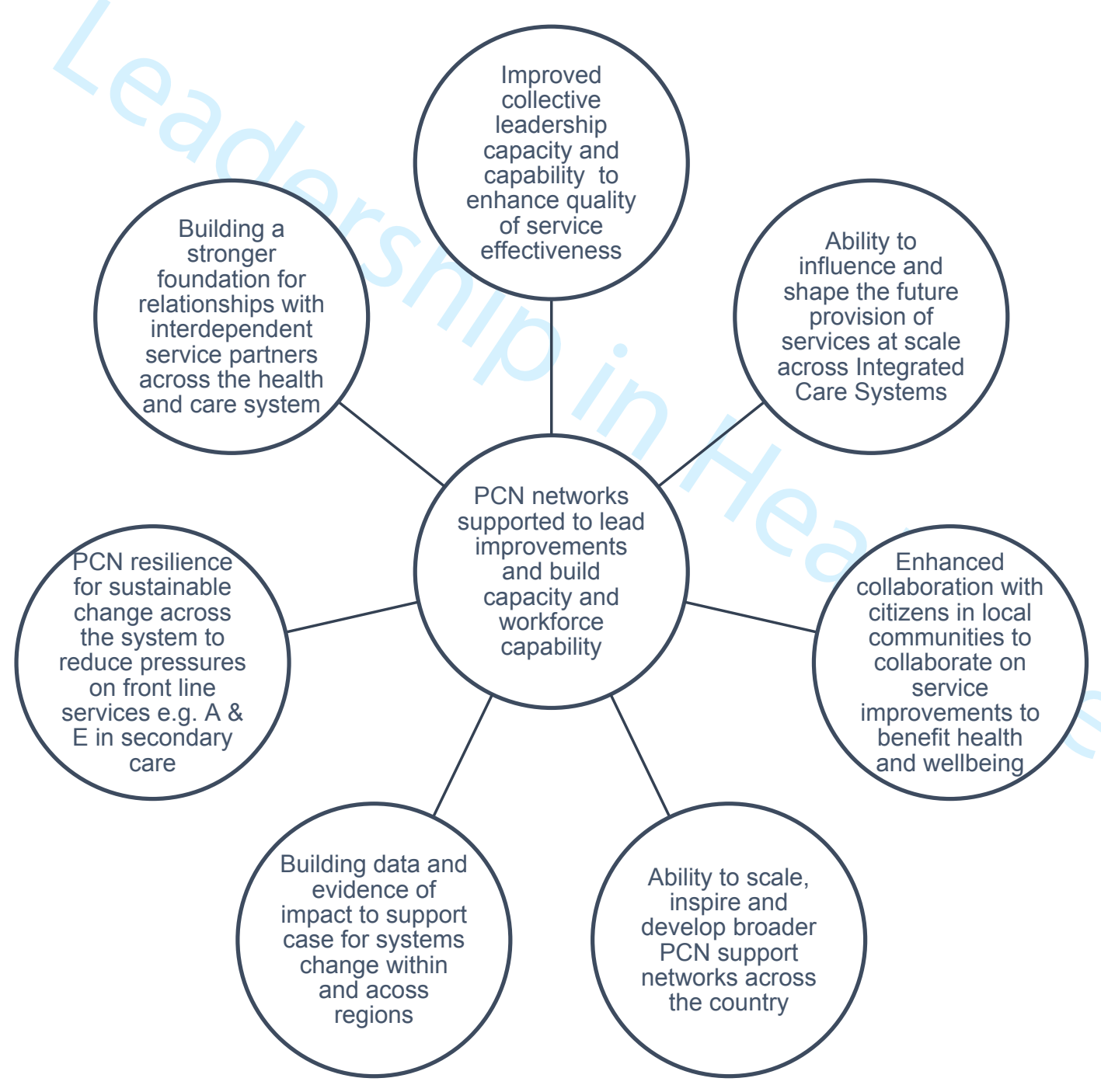




\section{Change Starts With Me: An impact evaluation of a multiprofessional leadership programme to support Primary Care Networks in the South East of England}

\section{Table of changes:}

\begin{tabular}{|c|c|}
\hline Reviewer 2 Comments & Changes \\
\hline $\begin{array}{l}\text { I would make a strong suggestion to } \\
\text { improve the presentation of the methods } \\
\text { and results to ensure that they are } \\
\text { transparent and evidenced in the } \\
\text { manuscript }\end{array}$ & $\begin{array}{l}\text { Methods and results sections have been } \\
\text { revamped and include new tables and } \\
\text { figures that illustrate an auditable trail of } \\
\text { how methods led to specific results with } \\
\text { detail of where evidence has been drawn } \\
\text { from across cohorts }\end{array}$ \\
\hline $\begin{array}{l}\text { 1. Originality: Does the paper contain new } \\
\text { and significant information adequate to } \\
\text { justify publication?: The paper is original } \\
\text { from what I can gleam, it aims to assess the } \\
\text { impact of a leadership programme in a PCN } \\
\text { (novel organisational structure). Therefore, } \\
\text { if the reporting was improved the work } \\
\text { would justify publication. } \\
\text { Narrow scope: The findings are limited to } \\
\text { one region in the UK, this limits the } \\
\text { international readership as there is no } \\
\text { discussion as to how the findings can help } \\
\text { explain other UK or international healthcare } \\
\text { systems. }\end{array}$ & $\begin{array}{l}\text { A PCN is not a novel organisational } \\
\text { structure it is part of the UK government's } \\
\text { restructure of services for the NHS Long } \\
\text { Term Plan (2019). There are now almost } \\
1300 \text { PCNs across the UK. All of the } \\
\text { background pertaining to their development } \\
\text { and relevance is now inserted in the } \\
\text { introduction and background Lines } 36-180 \text {. } \\
\text { The full manuscript has been reworked to } \\
\text { provide fuller evidence of reporting the } \\
\text { findings and discussing the results. } \\
\text { Discussion about how it has implications } \\
\text { more broadly nationally and internationally } \\
\text { now included in Lines } 626-635 \text { and } 669- \\
685 \text {. }\end{array}$ \\
\hline $\begin{array}{l}\text { 2. Relationship to Literature: Does the } \\
\text { paper demonstrate an adequate } \\
\text { understanding of the relevant literature in } \\
\text { the field and cite an appropriate range of } \\
\text { literature sources? Is any significant work } \\
\text { ignored?: Some current literature is citied } \\
\text { but it is minimal. One systematic review it } \\
\text { referenced. The authors do state that } \\
\text { "There is very little published evidence of } \\
\text { initiatives aimed at improving PCN } \\
\text { collaboration and leadership currently in the } \\
\text { literature." They do not provide evidence of } \\
\text { the statement. } \\
\text { However, the literature around leadership of } \\
\text { transformations is vast therefore I would } \\
\text { expect a brief discussion of the literature in } \\
\text { the healthcare domain. }\end{array}$ & $\begin{array}{l}\text { Study aim provided in Line 235-239. } \\
\text { Background to the rationale for developing } \\
\text { the programme and how it fits with both } \\
\text { more conventional leadership programmes } \\
\text { and approaches is now provided with an } \\
\text { emphasis on developing Primary Care } \\
\text { Network Teams in Lines } 91-228 \text {. The } \\
\text { discussion highlights evidence related to } \\
\text { the importance of developing team cultures } \\
\text { of learning, development, innovation and } \\
\text { improvement and why collective leadership } \\
\text { is more effective in sustaining person } \\
\text { centered safe and effective transformation } \\
\text { across systems generally in the paper } \\
\text { based on the very latest research evidence } \\
\text { by Manley and Jackson (2020), Cardiff et al } \\
\text { (2020) and Smith et al (2020). }\end{array}$ \\
\hline $\begin{array}{l}\text { There is no theoretical stance or leadership } \\
\text { theory cited. Why do the authors consider } \\
\text { leadership to be the factor that will } \\
\text { address the issues facing general } \\
\text { practice/primary care? }\end{array}$ & $\begin{array}{l}\text { Our stance is made clearer in the } \\
\text { background and discussion sections of the } \\
\text { paper. }\end{array}$ \\
\hline & \\
\hline
\end{tabular}




\begin{tabular}{|c|c|}
\hline $\begin{array}{l}\text { no study aim. What is the study trying to } \\
\text { do? This needs to be clear. }\end{array}$ & \\
\hline $\begin{array}{l}\text { The methodology is poor. There is no } \\
\text { evidence of an appropriate base of theory } \\
\text { or concepts. Design methods and analysis } \\
\text { are not well described. }\end{array}$ & $\begin{array}{l}\text { Study design has been strengthened by the } \\
\text { addition of Table } 1 \text { which describes the } \\
\text { methods used to address the impact } \\
\text { evaluation questions, the data sets } \\
\text { generated and how these were analysed } \\
\text { and how data has been triangulated. } \\
\text { Further evidence is provided in the text of } \\
\text { the relationship between these methods } \\
\text { and findings in lines } 229-557 \text {. }\end{array}$ \\
\hline $\begin{array}{l}\text { The study design is not clear - what data } \\
\text { was collected and in what order. } \\
\text { The authors talk about philosophical } \\
\text { assumptions - but give no indication as to } \\
\text { what they are for this particular study } \\
\text { "qualitative and quantitative data in a single } \\
\text { study and provides a better understanding } \\
\text { of } \\
\text { research problems than either approach } \\
\text { alone." This statement is very imprecise } \\
\text { and not cited }\end{array}$ & $\begin{array}{l}\text { The assumptions were specifically identified } \\
\text { in Box III Assumptions underpinning the } \\
\text { approach to impact evaluation and provide } \\
\text { the theoretical underpinnings to the } \\
\text { approach taken. Further Table } 1 \text { clearly } \\
\text { illustrates the methods used. }\end{array}$ \\
\hline $\begin{array}{l}\text { The authors state that "research leaders } \\
\text { from the England Centre for Practice } \\
\text { Development" undertook the impact } \\
\text { evaluation. }\end{array}$ & $\begin{array}{l}\text { Yes that is correct, Manley and Jackson } \\
\text { were then the Directors of the England } \\
\text { Centre for Practice Development and are } \\
\text { recognised leaders nationally and } \\
\text { internationally for research in systems } \\
\text { transformation. }\end{array}$ \\
\hline $\begin{array}{l}\text { The authors also state "Impact is defined as } \\
\text { 'making a positive difference' as a leader } \\
\text { individually and collectively, to one's own } \\
\text { practice, general practice, team, patients, } \\
\text { their experience and health outcomes." - } \\
\text { not citation is provided ad not } \\
\text { methodological description of the impact } \\
\text { methods are given } \\
\text { If this is an impact evaluation the methods } \\
\text { used to conduct this need to be } \\
\text { provided. The detail provided in box one } \\
\text { are not research methods - as suggested in } \\
\text { the text they are principles and } \\
\text { assumptions. What did the authors } \\
\text { actually do and measure? } \\
\text { The description of the analysis is not } \\
\text { acceptable "Data from each method was }\end{array}$ & $\begin{array}{l}\text { Lines } 245-265 \text { have been added to provide } \\
\text { foundation for how impact has been } \\
\text { measured and what this means in the } \\
\text { context of the study complemented by } \\
\text { Table } 1 \\
\text { Impact Defined by ESRC inserted and } \\
\text { linked to co-production -similar to Practice } \\
\text { development methodology stated in the } \\
\text { assumptions Box } 3 \\
\text { Table } 1 \text { has been embellished to make } \\
\text { clearer the methods, timeframes, data } \\
\text { analysis and insights } \\
\text { The research methods have been made } \\
\text { clearer in the context of the learning and } \\
\text { development processes and referenced }\end{array}$ \\
\hline
\end{tabular}


analysed" the reader does not know what data was collected from which method or how it was analysed

Table I - again does not provide a description of the research methods used or data collected. "Review" is mentioned a lot, but what did this review contain and how was it done

What method of triangulation did the authors use?

There is zero transparency in the analysis which leads to questions of validity of the findings. more explicitly. To provide much more detail would require a lot more words so we are hoping this will suffice

This has been expanded a little drawing on Pattons understanding of triangulation of qualitative data.
The audit trail in relation to data presented has been made much clearer across Tables and by inclusion of additional data tables and excerpts from participant transcripts across the cohorts. These can now be found in Lines 270-557 and by inclusion of additional boxes and tables of evidence

Introduction to the findings is presented in

4. Results: Are results presented clearly and analysed appropriately? Do the conclusions adequately tie together the other elements of the paper?: No introduction to the findings is presented.

The findings are presented by research question. It is not clear why different assessments were conducted in cohort 1 and 2 . The findings are descriptive with little evidence supporting statements from participants.

It is not clear what is presented in table 2. Is this raw or analysed data. There is no line from what was collected to what is presented.
Lines 269-273 and generally the linkage between data sets and findings is summarised in more detail under each impact question as a subheading

Supporting statements from participants are now included in Lines 269-557. Excerpts from participants are provided in the text and by the addition of Table 3 and 4 .

Table 2 is the co-created leadership impact framework that participants developed as part of their programme and used to assess their own and team leadership journey's against. It summarises what leadership means to them. It captures the enablers, attributes and outcomes of effective PCN team leadership at different levels of the system for a range of beneficiaries. Further elaboration of the enablers, attributes and outcomes are now provided in the text to illustrate key points in Lines 364-380.

Table 3 now clearly illustrates this. 
Some data is provided in Table 3. But the authors do not indicate which cohort or which participant each quote came from for example are these all GPs? Labels and cohorts are needed for the 9 quotes.

The write up of question 3 findings provide very little data (evidence) of what is presented. It is all descriptive information for example:

"quality improvement huddles (NHS Improvement, 2019). and Claims, Concerns and Issues (CCls) (Guba and Lincoln, 1989), were really helpful."

"Learning how to network, and present alongside colleagues from other practices experiencing similar workplace issues was a powerful force for learning."

Where is the evidence to support these statements?

The authors conclude the findings by saying there is strong evidence that the programme increases self-awareness - this is not true of the manuscript as it stands. I expect they do have the evidence but they have not presented in the manuscript in a way that is convincing to the reader
Implications for research, practice and/or society: Does the paper identify clearly any implications for research, practice and/or society? Does the paper bridge the gap between theory and practice? How can the research be used in practice (economic and commercial impact), in teaching, to influence public policy, in research (contributing to the body of knowledge)? What is the impact upon society (influencing public attitudes, affecting quality of life)? Are these implications consistent with the findings and conclusions of the paper?: No implications are provided. All the questions above need to form the discussion - rather than a
Evidence is now provided in much more detail in Lines 490-557 and integrated with participant insights linked to Tables 3 and 4

Table 2,3, 4 provide evidence of impact of the programme on individuals and their teams and the findings section of the paper illustrates this with excerpts from participant feedback.

With word allowance at premium we have addressed implications for practice and research in lines 559-635 and then in lines 671-685 
summary of the results and literature which

is currently provided.

if this is an impact evaluation it should be in the title. The current title makes little sense in comparison to what is presented int eh core text. For example - what is an integrated approach?

\section{Abstract}

Abstract needs to be re written for clarity

The study aim is not clear - please re-write in the purpose sub heading not in the methods. More detail is needed on the methods and analysis - mixed methods is too vague. There is reference to "the programme' with no indication as to what it is - earlier referred to as a framework.

"learning and development processes influential on leadership strategies used by participants in the workplace to achieve impact?" this is not a question

Please state what data was collected, using what methods and how was it analysed.

The originality statement is weak, can you summarise in the statement the actual impact you evaluated.

The introduction and background text need to be swapped in order. If is very difficult to read the detail of the programme before setting the scene - UK, GP, PCNs etc

'The Programme' is not named. Is this purposeful ? The reader needs to know who developed it, whether it is evidence-based, and what the components are. The current description is vague and more detail is required - this could be a summary of 'The Programme' provided in a text box. It is also not clear what the aim of the programme was - was it to develop self awareness? Was it focused on the induvial as per the title or the meso and macro as suggested in the text

A break down of participants by cohort needs to be clearer. This is only provided for the GPs. It is not clear why the Hobbs 2016 reference is cited here (this text should also be in the methods are part of the description of participants)

The title of the paper has been amended

The abstract has been revised to address these points
The introduction and background have been redeveloped based on the feedback from all three reviewers

The programme title is identified in lines 177 and 182. A section has been added that provides details of the programme along with Box 1 and 2 that describe the programme aims, principles and key learning strategies and processes. The programme focus has been made clearer

Lines 181-220 have been added to describe the programme in more detail and 


\begin{tabular}{|c|c|c|}
\hline \multirow[t]{2}{*}{$\begin{array}{l}\text { Background } \\
\text { Please provide a citation for the sentence } \\
\text { "Each PCN is likely to have a GP as the } \\
\text { clinical lead who will be responsible for } \\
\text { strategic and clinical leadership to help } \\
\text { support change across primary and } \\
\text { community health services, as well as } \\
\text { overseeing service delivery." } \\
\text { GMC's - expand }\end{array}$} & & $\begin{array}{l}\text { Developed further with supporting } \\
\text { references line } 57 \text { National Association of } \\
\text { Primary Care. }\end{array}$ \\
\hline & & $\begin{array}{l}\text { GMC reference removed and more focus } \\
\text { placed on Primary care instead. }\end{array}$ \\
\hline $\begin{array}{l}\text { The discussion starts with strengths. This } \\
\text { should be at the end of the discussion. Box } \\
\mathbf{2} \text { does not need to be in a box and } \\
\text { should be included in the text. } \\
\text { The authors should re-write the discussion } \\
\text { to briefly summarise what the study aimed } \\
\text { to do, why it was important and then follow } \\
\text { up with a summary of the findings in relation } \\
\text { to the literature. } \\
\text { There are hints to the leadership literature } \\
\text { in the discussion that should be included in } \\
\text { the background West et al. This would set } \\
\text { the context for the study which was lacking. } \\
\text { The authors describe "The use of practice } \\
\text { development methodology combined } \\
\text { with concepts of transformational } \\
\text { clinical leadership" what is this in relation } \\
\text { to this paper? Is the implication that this is } \\
\text { what was done in this study? } \\
\text { The discussion would be improved if the } \\
\text { detail of the programme had been } \\
\text { provided in the study. Parts of the } \\
\text { programme are discussed in the discussion } \\
\text { ( eg peer consulting model) without any } \\
\text { previous mention of them in the text. }\end{array}$ & & $\begin{array}{l}\text { The discussion section of the paper has } \\
\text { been reworked to address these points. } \\
\text { Practice development draws on principles } \\
\text { of collaboration, inclusion and participation } \\
\text { of collective voices to provide opportunities } \\
\text { for everyone's contributions to be heard } \\
\text { and valued. This is really central to work } \\
\text { that is transformational hence the concept } \\
\text { of transformational leadership is important } \\
\text { as summarised in Box III Assumptions } \\
\text { underpinning the approach to impact } \\
\text { evaluation. } \\
\text { Detail of the programme is now provided in } \\
\text { a designated section complemented by } \\
\text { content in Box } 1 \text { and } 2 \text {. }\end{array}$ \\
\hline $\begin{array}{l}\text { No mention of peer consulting method prior } \\
\text { to discussion }\end{array}$ & 322 & $\begin{array}{l}\text { Added to methods along with more } \\
\text { programme detail in lines } 144-149, \text { and } \\
\text { lines } 430-448 \text {. }\end{array}$ \\
\hline
\end{tabular}




\section{Limitations - the limitations are restricted mainly to the content of the programme. What are the limitations of the research methods and therefore the consequences on the authors findings.}

The findings are limited to one region in the UK, this limits the international readership as there is no discussion as to how the findings can help explain other UK or international healthcare systems.

The conclusion is generic and should be specific to the aims and finding of the work

A general proof read for typos is needed there are many errors and formatting mistakes

The introduction and background provide no study aim. What is the study trying to do? This needs to be clear.

Title - if this is an impact evaluation it should be in the title. The current title makes little sense in comparison to what is presented in the core text. For example what is an integrated approach ?

The paper reads as an impact evaluation of a leadership development programme (which is not specified)

\begin{tabular}{|c|c|c|}
\hline Reviewer 3 Comments & $\begin{array}{c}\text { Line } \\
\text { Number }\end{array}$ & Changes \\
\hline $\begin{array}{l}\text { I felt that the description of PCNs, what they } \\
\text { are, all the info in the background about their } \\
\text { value to the system should come at the } \\
\text { beginning of the paper after the first } \\
\text { sentence, as context. I personally believe } \\
\text { PCNs are one of the highlights of the NHS } \\
\text { because of how they work to address health } \\
\text { and social problems in the community, and } \\
\text { this should be emphasised. }\end{array}$ & $45-55$ & $\begin{array}{l}\text { Text re-ordered to address this point, A lot } \\
\text { more detail on the background to PCN } \\
\text { development,their relationship to Integrated } \\
\text { Care Systems and the challenges they face } \\
\text { are now provided in the introduction (L42-78 } \\
\text { ) and in the Background section (L91-176) }\end{array}$ \\
\hline $\begin{array}{l}\text { How were the cohorts selected and did they } \\
\text { volunteer? Who funded the program? }\end{array}$ & $125-162$ & $\begin{array}{l}\text { Programme details, recruitment, selection } \\
\text { and details of funders has been created in } \\
\text { Lines } 181-228\end{array}$ \\
\hline $\begin{array}{l}\text { I believe the literature review emphasising } \\
\text { the leadership (and perhaps the kind of } \\
\text { leadership) that adds value to PCN should } \\
\text { be a standalone paragraph. Falling out of the } \\
\text { literature review and context should be how } \\
\text { the program was intended to fill the gaps. A } \\
\text { literature review is strictly speaking part of } \\
\text { the methodology and would help explain } \\
\text { your program content. }\end{array}$ & $63-124$ & $\begin{array}{l}\text { The literature review is provided in the } \\
\text { Background to the paper L91-176 and has } \\
\text { been further developed to reflect the value of } \\
\text { PCNs and current challenges. } \\
\text { A section has been added (line } 177-180 \text { ) to } \\
\text { explain how the programme was designed to } \\
\text { address the gap in evidence for this type of } \\
\text { programme. }\end{array}$ \\
\hline
\end{tabular}




\begin{tabular}{|l|l|l|}
\hline $\begin{array}{l}\text { What does the Hobbs et al, 2016 reference } \\
\text { refer to on line } 38 \text { when describing the } \\
\text { cohorts refer to? The description of what the } \\
\text { program did, how it was received, how it } \\
\text { worked and how it was evaluated by the } \\
\text { participants - much of this is already there. } \\
\text { But it could be described in more detail. }\end{array}$ & 309 & $\begin{array}{l}\text { Hobbs reference removed. We have } \\
\text { provided more description of the } \\
\text { programme in a dedicated section lines } \\
181-228\end{array}$ \\
\hline $\begin{array}{l}\text { The Results should be the perceived } \\
\text { strengths it was perceived to bring to the } \\
\text { participants and also the network itself. It } \\
\text { could be tied back to the literature. }\end{array}$ & 206-461 & $\begin{array}{l}\text { We have linked the results and discussion } \\
\text { section so that the benefits and impact of the } \\
\text { programme is made clearer in the Results } \\
\text { and Discussion sections Lines 269-635. }\end{array}$ \\
$\begin{array}{l}\text { Finally - just perhaps a word or two about } \\
\text { relevance of the program for other } \\
\text { networks in terms of the strengths the } \\
\text { program brings for dealing with a rapidly } \\
\text { changing environment. }\end{array}$ & 39 & $\begin{array}{l}\text { Addional tables have been added to show } \\
\text { an auditable trail of evidence of impact for } \\
\text { participants. }\end{array}$ \\
\hline
\end{tabular}

